\title{
Synthesis and characterization of push-pull bithiophene and thieno $[3,2-b]$ thiophene derivatives bearing an ethyne linker as sensitizers for dye-sensitized solar cells
}

\author{
Sara S.M. Fernandes ${ }^{\text {a }}$, I. Mesquita ${ }^{\text {b }}$, L. Andrade ${ }^{\text {b }}$, A. Mendes ${ }^{\text {b }}$, Licínia L.G. Justino ${ }^{\text {c }}$, \\ Hugh D. Burrows ${ }^{\mathrm{c}}$, M. Manuela M. Raposo ${ }^{\mathrm{a}, *}$ \\ a Centro de Química, Universidade do Minho, Campus de Gualtar, 4710-057, Braga, Portugal \\ ${ }^{\mathrm{b}}$ LEPABE, Faculdade de Engenharia, Universidade do Porto, rua Dr. Roberto Frias, 4200-465, Porto, Portugal \\ c Centro de Química, Departamento de Química, Universidade de Coimbra, 3004-535, Coimbra, Portugal
}

\section{A R T I C L E I N F O}

\section{Article history:}

Received 23 February 2017

Received in revised form

14 June 2017

Accepted 18 June 2017

Available online 21 June 2017

\section{Keywords:}

Dye sensitized solar cells

Metal-free organic dyes

Bithiophene

Thieno[3,2- $b$ ] thiophene

Cyanoacetic acid

Rhodanine-3-acetic acid

Co-adsorption

\begin{abstract}
A B S T R A C T
Five push-pull heterocyclic dyes $\mathbf{4 - 7}$, and $\mathbf{9}$ were synthesized and characterized in order to study the variations in the optical, electronic and photovoltaic properties induced by structural modifications, i.e. different spacer units and anchoring groups. The final push-pull conjugated dyes $\mathbf{6 - 7}$ and $\mathbf{9}$ are formed by a $\mathrm{N}, \mathrm{N}$-dimethylaniline donor moiety conjugated with bithiophene, ethynyl-bithiophene or ethynylthieno[3,2-b]thiophene spacers and cyanoacetic acid or rhodanine-3-acetic acid as anchoring group. The synthesis of the precursor aldehydes 4-5 was accomplished through a Sonogashira coupling, on the other hand, compound $\mathbf{8}$ was prepared by Suzuki coupling. Knoevenagel condensation of aldehydes $\mathbf{4 , 5}$ and $\mathbf{8}$ with cyanoacetic acid or rhodamine-3-acetic acid afforded the final push-pull dyes $\mathbf{6 , 7}$ and $\mathbf{9}$. Information on conformation, electronic structure and electron distribution was obtained by DFT and TDDFT calculations. This multidisciplinary study regarding the evaluation of the optical, redox and photovoltaic properties of the dyes reveals that compound 7, bearing an ethynyl-bithiophene spacer conjugated with a cyanoacetic acid anchoring group, has the highest conversion efficiency $(3.51 \%)$ as dye sensitizer in nanocrystalline $\mathrm{TiO}_{2}$ solar cells. Co-adsorption studies were also performed for dyes $\mathbf{6}-\mathbf{7}$ with $\mathbf{N 1 9}$ as co-adsorbent, and this enhanced dye efficiencies by $33-45 \%$. The best cell performance was obtained by co-adsorbing N719 and dye 7 (75/25 vol\%) with $4.66 \%$ efficiency.
\end{abstract}

() 2017 Elsevier B.V. All rights reserved.

\section{Introduction}

Metal free donor-acceptor organic dyes have shown interesting features to be used as sensitizers in dye sensitized solar cells (DSSCs) and thus replacing ruthenium based dyes. These solar cells based on nanocrystalline $\mathrm{TiO}_{2}$ electrodes are seen as a very promising and attractive photovoltaic technology due to high incident solar light to electricity conversion efficiency, good performance in low light conditions and different solar incident angles, low maintenance, good long-term stability, cheap and sustainable components, multi-colour range possibilities, semi-transparency and flexibility. Over the last two decades, a wide range of structural modifications to the donor or acceptor group and $\pi$-bridge has

\footnotetext{
* Corresponding author.

E-mail address: mfox@quimica.uminho.pt (M.M.M. Raposo).
}

been investigated in order to obtain organic chromophores with high performance for DSSCs [1-17].

In a photovoltaic device, the dye sensitizer plays an important role in the light absorption, conversion efficiency and the stability of the device. It should possess some essential characteristics, such as a push-pull structure (donor- $\pi$-bridge-acceptor), promoting efficient charge transfer and separation on going from the ground state to the excited state, broad spectral response (visible and nearinfrared region), photostability, controlled aggregation and charge recombination, appropriate electronic energies (HOMO, LUMO), good intramolecular charge transfer, and an anchoring group to strongly bind onto the semiconductor surface [1-18]. Additionally, metal free dyes show advantages such as easy and low cost synthesis and purification, diversity of molecular structural modifications which offer nearly infinite possibilities for easily tuning the photophysical and electrochemical properties, and high molar extinction coefficients. Metal free sensitizers, such as synthetic 
organic [1-17] and natural dyes [19], have, therefore, received attention as an alternative to metal complexes for DSSC applications. However, the lack of absorbance of red and near infra-red light of these compounds is still an obstacle which needs to be overcome.

Donor groups commonly used are $N, N$-dialkylamine, diphenylamine, triphenylamine, carbazole, indoline, etc [20]. Additionally, electron-rich heterocycles (thiophene, pyrrole, furan) can be used as auxiliary donor groups in these push-pull systems. Usual spacers or $\pi$-conjugated bridges are ethene, ethyne, benzene or electronrich heterocycles [1-15,21-27].

Previously, dye sensitizers applied in solar cells were mainly ruthenium complexes, consisting of the central metal ion complexed with organic ligands containing an anchoring group. Ruthenium is a heavy metal, not widely found in nature, and its toxicity presents a risk for the environment. Moreover, complicated synthetic processes and difficult purification of the dyes limit the use of Ru-based dye sensitizers in terms of cost efficiency and environmental friendliness. However, transition metal complexes still play an important role in DSSC development, since many of the most efficient and stable dye sensitizers are $\mathrm{Ru}(\mathrm{II})$-based complexes, due to intense metal-to-ligand charge transfer transitions. The best photovoltaic efficiency in terms of conversion yield and stability, surpassing $11 \%$, have been achieved by polypyridyl complexes of Ru and $\mathrm{Zn}$-porphyrin based dyes [28-34].

The first metal free organic dyes used as sensitizers for DSSCs showed poor performances, but since then several organic compounds have been developed and the corresponding photovoltaic devices show good performance, with similar efficiencies to the best Ru complexes ( 12\%) [35-45]. Recently a high conversion efficiency of over $14 \%$ was reported using collaborative sensitization between two organic dyes bearing two different anchoring groups [46].

Very frequently, the most efficient DSSCs, contain thiophene groups (e.g. oligothiophenes, fused thiophenes, etc.) and ethyne units as $\pi$-spacers because of their excellent charge-transport properties, good $\pi$-conjugation and high planarity, which allow the best photovoltaic performances [1-15,35-45]. Following from these earlier achievements, we report the synthesis and evaluation of optical, redox, and photovoltaic properties of three push-pull organic dyes bearing a $\mathrm{N}, \mathrm{N}$-dimethylaniline donor moiety conjugated with 2,2'-bithiophene, ethynyl-2,2'-bithiophene or ethynylthieno[3,2- $b]$ thiophene spacers and cyanoacetic acid or rhodanine3 -acetic acid as anchoring group. These new synthesis routes are then coupled with a theoretical study of the dyes using density functional theory (DFT) and time dependent DFT (TDDFT).

\section{Experimental section}

\subsection{Materials and instruments}

4-Ethynyl- $N, N$-dimethylaniline and cyanoacetic acid were purchased from Aldrich. Rhodanine-3-acetic acid was purchased from Alfa Aesar. All commercially available reagents and solvents were used as received. 5-Bromothieno[3,2-b]thiophene-2-carbaldehyde [47], 5'-bromo-2,2'-bithiophene-5-carbaldehyde [48], and 5formyl-5'-(4-N,N-dimethylaminophenyl)-2,2'-bithiophene [49] were prepared using the same synthetic methodologies previously reported by us.

Reaction progress was monitored by thin layer chromatography, $0.25 \mathrm{~mm}$ thick precoated silica plates (Merck Fertigplatten Kieselgel 60 F254), and spots were visualised under UV light. Purification was achieved by silica gel column chromatography (Merck Kieselgel, 230-400 mesh). NMR spectra were obtained on a BruckerG Avance II 400 at an operating frequency of $400 \mathrm{MHz}$ for ${ }^{1} \mathrm{H}$ and $100.6 \mathrm{MHz}$ for ${ }^{13} \mathrm{C}$, using the solvent peak as internal reference. The solvents are indicated in parenthesis before the chemical shifts values $(\delta$ relative to TMS). Peak assignments were made by comparison of chemical shifts, peak multiplicities and $J$ values, and were supported by spin decoupling-double resonance and bidimensional heteronuclear HMBC (heteronuclear multiple bond coherence) and HMQC (heteronuclear multiple quantum coherence) techniques. Melting points were determined on a Gallenkamp apparatus and are uncorrected. Infrared spectra were recorded on a BOMEM MB 104 spectrophotometer. UV-Vis absorption spectra were obtained using a Shimadzu UV/2501PC spectrophotometer. Fluorescence spectra were collected using a FluoroMax-4 spectrofluorometer. The relative fluorecence quantum yields were determined using fluorescein in a $0.1 \mathrm{M}$ aqueous solution of $\mathrm{NaOH}\left(\phi_{\mathrm{F}}=0.79\right)$ [50]. Mass spectrometry analysis were performed at the C.A.C.T.I. Unidad de Espectrometria de Masas of the University of Vigo, Spain.

\subsection{Synthesis}

\subsubsection{General procedure for the synthesis of aldehydes 4-5 through Sonogashira coupling}

Aldehydes 2 [47] or 3 [48] (0.81 mmol) were coupled with 4ethynyl- $N, N$-dimethylaniline $1(0.114 \mathrm{~g}, 0.78 \mathrm{mmol})$, in a mixture of THF (10 mL), trimethylamine $(6 \mathrm{~mL}), \mathrm{Pd}\left(\mathrm{PPh}_{3}\right)_{2} \mathrm{Cl}_{2}(0.023 \mathrm{~g}$, $0.02 \mathrm{mmol})$ and copper iodide $(0.002 \mathrm{~g}, 0.01 \mathrm{mmol})$, at reflux under nitrogen. The reaction was monitored by TLC, which determined the reaction time $(16 \mathrm{~h})$. After cooling, $10 \mathrm{~mL}$ of water were added and the reaction mixture was extracted with dichloromethane $(3 \times 20 \mathrm{~mL})$. The combined organic layers were dried over anhydrous $\mathrm{MgSO}_{4}$, filtered, and the solvent evaporated under reduced pressure. The crude products were purified by column chromatography (silica gel, mixtures of chloroform and light petroleum of increasing polarity) to give the pure compounds $\mathbf{4}-\mathbf{5}$.

2.2.1.1. 5-(2'-(4"-Dimethylamino)phenyl)ethynyl)thieno[3,2-b]thiophene-2-carbaldehyde 4. Orange solid, $\eta$ 35\%. Mp. 203-205 ${ }^{\circ} \mathrm{C}$. UV (ethanol): $\lambda_{\max } \mathrm{nm}\left(\varepsilon, \mathrm{M}^{-1} \mathrm{~cm}^{-1}\right) 409,(34,705)$. IR (liquid film) $v$ 2180, 1664, 1530, 1406, $1226 \mathrm{~cm}^{-1} .{ }^{1} \mathrm{H}$ NMR (DMSO-d, $400 \mathrm{MHz}$ ) $\delta 2.96\left(\mathrm{~s}, 6 \mathrm{H}, 2 \mathrm{xNCH}_{3}\right), 6.72\left(\mathrm{~d}, 2 \mathrm{H}, \mathrm{H}-3^{\prime \prime}\right.$ and $\left.\mathrm{H}-5^{\prime \prime}, J=7.0 \mathrm{~Hz}\right), 7.39$ (d, $2 \mathrm{H}, \mathrm{H}-2^{\prime \prime}$ and $\left.\mathrm{H}-6^{\prime \prime}, J=7.0 \mathrm{~Hz}\right), 7.74(\mathrm{~s}, 1 \mathrm{H}, \mathrm{H}-6), 8.34(\mathrm{~s}, 1 \mathrm{H}, \mathrm{H}-3)$, $9.98(\mathrm{~s}, 1 \mathrm{H}, \mathrm{CHO}) \mathrm{ppm} .{ }^{13} \mathrm{C}$ NMR (DMSO- $\left.d_{6}, 100 \mathrm{MHz}\right) \delta 39.6,80.9$, 98.9, 106.8, 111.8, 124.1, 130.9, 131.1, 132.6, 138.6, 144.3, 145.5, 150.6, $184.8 \mathrm{ppm}$. MS (EI) $m / z(\%)=312\left([\mathrm{M}+\mathrm{H}]^{+}, 15\right), 311\left([\mathrm{M}]^{+}, 100\right), 310$ (29), 295 (11). HMRS: $m / z$ (EI) for $\mathrm{C}_{17} \mathrm{H}_{13} \mathrm{NOS}_{2}$; calcd: 311.0439; found: 311.0437.

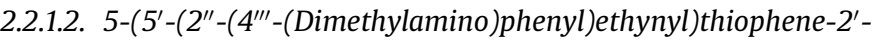
yl)thiophene-2-carbaldehyde 5. Orange solid, $\eta$ 77\%. Mp. $191-193{ }^{\circ} \mathrm{C}$ (lit. $200-203{ }^{\circ} \mathrm{C}$ [51]). ${ }^{1} \mathrm{H}$ NMR (DMSO- $d_{6}, 400 \mathrm{MHz}$ ) $\delta 2.96\left(\mathrm{~s}, 6 \mathrm{H}, \mathrm{NCH}_{3}\right), 6.71\left(\mathrm{~d}, 2 \mathrm{H}, \mathrm{H}-3^{\prime \prime \prime}\right.$ and $\left.\mathrm{H}-5^{\prime \prime \prime}, J=8.8 \mathrm{~Hz}\right), 7.32(\mathrm{~d}$, $1 \mathrm{H}, \mathrm{H}-3^{\prime}, J=4.0 \mathrm{~Hz}$ ), 7.35 (d, $2 \mathrm{H}, \mathrm{H}-2^{\prime \prime \prime}$ and $\left.\mathrm{H}-6^{\prime \prime \prime}, J=9.2 \mathrm{~Hz}\right), 7.56$ $\left(\mathrm{m}, 2 \mathrm{H}, \mathrm{H}-4\right.$ and $\left.\mathrm{H}-4^{\prime}\right), 8.00(\mathrm{~d}, 1 \mathrm{H}, \mathrm{H}-3, J=4.0 \mathrm{~Hz}), 9.88(\mathrm{~s}, 1 \mathrm{H}, \mathrm{CHO})$ ppm.

\subsubsection{General method of synthesis for compounds $\mathbf{6}-\mathbf{7}$}

To a mixture of aldehyde $\mathbf{4}$ or $\mathbf{5}(0.25 \mathrm{mmol})$ and 2-cyanoacetic acid $(0.30 \mathrm{mmol})$ in ethanol $(15 \mathrm{~mL})$ was added 4 drops of $N$-triethylamine. The reaction mixture was heated under reflux during $6 \mathrm{~h}$ and then cooled to room temperature. The mixture was concentrated by partial evaporation of the solvent and diethyl ether was added to induce precipitation. The precipitates obtained were filtered and washed with ethyl ether to give the pure products 6-7.

2.2.2.1. 2-Cyano-3-(2'-(2"'-(4'"'-(dimethylamino)phenyl)ethynyl) thieno[3,2-b]thiophen-5'-yl)acrylic acid 6. Orange solid, $\eta$ 53\%. Mp. 
215-217 ${ }^{\circ} \mathrm{C}$. UV (ethanol): $\lambda_{\max } \mathrm{nm}\left(\varepsilon, \mathrm{M}^{-1} \mathrm{~cm}^{-1}\right) 421$, (33,786). IR (liquid film) v 3420, 2361, 2194, 1610, 1531, $1363 \mathrm{~cm}^{-1} .{ }^{1} \mathrm{H}$ NMR $\left(\mathrm{DMSO}-d_{6}, 400 \mathrm{MHz}\right) \delta 2.96\left(\mathrm{~s}, 6 \mathrm{H}, 2 \mathrm{xNCH}_{3}\right), 6.71\left(\mathrm{~d}, 2 \mathrm{H}, \mathrm{H}-3^{\prime \prime \prime}\right.$ and $\left.\mathrm{H}-5^{\prime \prime \prime}, J=9.2 \mathrm{~Hz}\right), 7.38$ (d, 2H, H-2'" and $\left.\mathrm{H}-6^{\prime \prime \prime}, J=8.8 \mathrm{~Hz}\right), 7.70(\mathrm{~s}, 1 \mathrm{H}$, $\left.\mathrm{H}-3^{\prime}\right), 7.98\left(\mathrm{~s}, 1 \mathrm{H}, \mathrm{H}-6^{\prime}\right), 8.15(\mathrm{~s}, 1 \mathrm{H},=\mathrm{CH}) \mathrm{ppm} .{ }^{13} \mathrm{C}$ NMR (DMSO- $d_{6}$, $100.6 \mathrm{MHz}$ ) $\delta 43.5,81.1,97.8,107.1,111.8,119.1,124.1,127.2,128.0$, $132.5,138.3,140.4,141.0,142.2,150.5 \mathrm{ppm}$. MS (ESI) $\mathrm{m} / \mathrm{z}(\%)=379$ $\left([\mathrm{M}+\mathrm{H}]^{+}, 100\right), 364$ (13). HRMS: $\mathrm{m} / \mathrm{z}$ (ESI) found 379.0569; $\mathrm{C}_{20} \mathrm{H}_{15} \mathrm{~N}_{2} \mathrm{O}_{2} \mathrm{~S}_{2}$ requires 379.0497 .

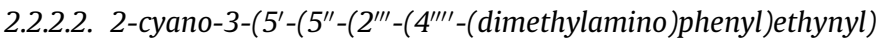
thiophen-2"-yl)thiophen-2'-yl)acrylic acid 7. Red solid. $\eta$ 81\%. Mp. 204-207 ${ }^{\circ} \mathrm{C}$. (lit. $235-245{ }^{\circ} \mathrm{C}$ [51]) ${ }^{1} \mathrm{H}$ NMR (DMSO-d $d_{6}, 400 \mathrm{MHz}$ ) $\delta 2.96(\mathrm{~s}, 6 \mathrm{H}, \mathrm{NCH}), 6.71\left(\mathrm{~d}, 2 \mathrm{H}, \mathrm{H}-3^{\prime \prime \prime \prime}\right.$ and $\left.\mathrm{H}-5^{\prime \prime \prime \prime}, J=8.8 \mathrm{~Hz}\right), 7.28$ (d, $\left.1 \mathrm{H}, \mathrm{H}-3^{\prime \prime}, J=3.6 \mathrm{~Hz}\right), 7.35$ (d, $2 \mathrm{H}, \mathrm{H}-2^{\prime \prime \prime \prime}$ and $\mathrm{H}-6^{\prime \prime \prime \prime}, J=8.8 \mathrm{~Hz}$ ), 7.41 (d, $\left.1 \mathrm{H}, \mathrm{H}-4^{\prime \prime}, J=3.6 \mathrm{~Hz}\right), 7.45\left(\mathrm{~d}, 1 \mathrm{H}, \mathrm{H}-4^{\prime}, J=4.0 \mathrm{~Hz}\right), 7.66(\mathrm{~d}, 1 \mathrm{H}$, $\left.\mathrm{H}-3^{\prime}, J=4.0 \mathrm{~Hz}\right), 8.04(\mathrm{~s}, 1 \mathrm{H},=\mathrm{CH}) \mathrm{ppm}$.

\subsubsection{Synthesis of rhodanine dye $\mathbf{9}$}

To a mixture of aldehyde 8 [49] $(0.060 \mathrm{~g}, 0.19 \mathrm{mmol})$ and rhodanine-3-acetic acid $(0.055 \mathrm{~g}, 0.29 \mathrm{mmol})$ in toluene $(15 \mathrm{~mL})$ was added 2 drops of concentrated acetic acid. The reaction mixture was heated under reflux during $6 \mathrm{~h}$ and then cooled to room temperature. The organic layer was extracted with chloroform $(200 \mathrm{~mL})$, washed with brine, and dried over anhydrous $\mathrm{MgSO}_{4}$. Evaporation of the solvent under reduced pressure gave the crude product, which was crystallized from hexane to give the pure product 9. Brown solid, $\eta 31 \%$. Mp. $199-201{ }^{\circ} \mathrm{C}$. UV (ethanol): $\lambda_{\max }$ $\mathrm{nm}\left(\varepsilon, \mathrm{M}^{-1} \mathrm{~cm}^{-1}\right) 430,(12,450)$. IR (liquid film) $v 3360,2676,1702$, $1585,1346,1279 \mathrm{~cm}^{-1} .{ }^{1} \mathrm{H}$ NMR (DMSO- $\left.d_{6}, 400 \mathrm{MHz}\right) \delta 2.95(\mathrm{~s}, 6 \mathrm{H}$, $\left.2 \mathrm{xNCH}_{3}\right), 4.61\left(\mathrm{~s}, 2 \mathrm{H}, \mathrm{CH}_{2}\right), 6.74\left(\mathrm{~d}, 2 \mathrm{H}, \mathrm{H}-3^{\prime \prime \prime \prime}\right.$ and $\left.\mathrm{H}^{-5^{\prime \prime \prime \prime}}, J=8.4 \mathrm{~Hz}\right)$, 7.34 (d, 1H, H-4"',$J=3.6 \mathrm{~Hz}$ ), 7.49-7.55 (m, 4H, H-2 ${ }^{\prime \prime \prime \prime}, \mathrm{H}-6^{\prime \prime \prime \prime}, \mathrm{H}-3^{\prime \prime \prime}$ and $\left.\mathrm{H}-4^{\prime \prime}\right), 7.75\left(\mathrm{~d}, 1 \mathrm{H}, \mathrm{H}-3^{\prime \prime}, J=3.6 \mathrm{~Hz}\right), 8.08(\mathrm{~s}, 1 \mathrm{H},=\mathrm{CH}) \mathrm{ppm} .{ }^{13} \mathrm{C}$ NMR (DMSO- $\left.d_{6}, 100 \mathrm{MHz}\right) \delta 43.7,111.8,112.3,118.2,120.6,122.5$, 125.0, 126.3, 126.43, 127.8, 131.6, 135.1, 138.1, 145.6, 146.4, 150.3, 166.1, 167.2, 191.6 ppm. MS (ESI) $\mathrm{m} / \mathrm{z}(\%)=391$ (11), 315 (17), 314 (100), 313 (24), 299 (14). HRMS: $\mathrm{m} / \mathrm{z}$ (ESI) $[\mathrm{M}+\mathrm{H}]^{+}$found 487.0275; $\mathrm{C}_{22} \mathrm{H}_{19} \mathrm{~N}_{2} \mathrm{O}_{3} \mathrm{~S}_{4}$ requires 487.0279 .

\subsection{Cyclic voltammetry}

The electrochemical measurements were performed using an AUTOLAB electrochemical station and a three electrode cell equipped with a vitreous carbon disc working electrode ( $3 \mathrm{~mm})$, a platinum wire as counter-electrode and an $\mathrm{Ag} / \mathrm{AgCl}$ electrode as reference electrode. The concentration of dyes was $1 \mathrm{mM}$ with $1 \mathrm{mM}$ of $\left[\mathrm{NBu}_{4}\right]\left[\mathrm{BF}_{4}\right]$ as supporting electrolyte in dry $\mathrm{N}, \mathrm{N}$-dymethylformamide solvent. Cyclic voltammetry was conducted at different scan-rates $\left(20,50,100\right.$ and $\left.200 \mathrm{mVs}^{-1}\right)$ and the solutions were deoxygenated bubbling nitrogen before each measurement. The electrode potentials were measured against the potential of the $\mathrm{Fc}^{+} / \mathrm{Fc}$ redox couple, as usual for non-aqueous solvents [52].

\subsection{DSSC preparation}

A dye-sensitized solar cell consists of: i) a $\mathrm{TiO}_{2}$ mesoporous layer where dye molecules are adsorbed, both comprising the working electrode; ii) a platinum counter-electrode; and iii) the electrolyte containing the iodide/triiodide redox couple. To prepare the working electrodes, FTO glasses (TCO22-7, $2.2 \mathrm{~mm}$ thickness, $7 \Omega$ / square, Solaronix, Switzerland) were used, cleaned in a detergent solution using ultrasonic bath rinsed with water and dried at $60^{\circ} \mathrm{C}$. After treating in a UV-O ${ }_{3}$ system for $15 \mathrm{~min}$, the FTO substrates were immersed into a $40 \mathrm{mM}$ aqueous $\mathrm{TiCl}_{4}$ solution at $70{ }^{\circ} \mathrm{C}$ for 20 min, washed with ethanol and dried with $\mathrm{N}_{2}$. A layer of $\mathrm{TiO}_{2}$ paste (Ti-Nanoxide T/SP, Solaronix, Switzerland) was coated on the FTO glass by screen-printing, kept at room temperature for $20 \mathrm{~min}$ and then dried for $5 \mathrm{~min}$ at $120^{\circ} \mathrm{C}$. The screen-printing procedure was repeated 2 more times, in order to achieve 3 layers of $\mathrm{TiO}_{2}$ paste $\left(0.2 \mathrm{~cm}^{2}\right.$ of circular active area, and $12 \mu \mathrm{m}$ of thickness). After drying the photoelectrode at $120^{\circ} \mathrm{C}$, it was gradually heated $\left(10^{\circ} \mathrm{C}\right.$ $\mathrm{min}^{-1}$ ) up to $475{ }^{\circ} \mathrm{C}$ for $30 \mathrm{~min}$. The $\mathrm{TiO}_{2}$ electrode was then immersed into a $0.5 \mathrm{mM}$ dye solution in ethanol and kept at room temperature for $12 \mathrm{~h}$.

To prepare the counter electrodes, two holes were made in the FTO glass using a drilling machine with a diamond tip. The FTO substrates were then washed as described before. Pt catalyst (Platisol T/SP, Solaronix, Switzerland) was deposited on the FTO side of the glass by screen-printing and then heated up to $450{ }^{\circ} \mathrm{C}$ for $10 \mathrm{~min}$.

The dye-covered $\mathrm{TiO}_{2}$ electrode and the Pt counter-electrode were assembled into a sandwich type cell and sealed with a hotmelt gasket of $25 \mu \mathrm{m}$ thickness - Surlyn (Meltonix 1170-25, Solaronix, Switzerland) by hot-pressing. The electrolyte (Iodolyte AN-50, Solaronix, Switzerland) was injected into the cell through the holes presented in the counter-electrode side. These holes were then sealed by Surlyn ${ }^{\circledR}$ and a cover glass using a soldering iron.

Two types of co-sensitization of $\mathrm{TiO}_{2}$ films were accomplished: i) by mixing different volume fractions of the sensitized organic dyes 6-7 with the reference dye $\mathbf{N 7 1 9}$ at room temperature for $12 \mathrm{~h}$ and ii) sequential co-adsorption of $12 \mathrm{~h}$ dipping time of dye N719, followed by $12 \mathrm{~h}$ dipping in the reported dyes $\mathbf{6}-\mathbf{7}$.

\subsection{DSSC characterization measurements}

A $150 \mathrm{~W}$ xenon light source (Oriel class a solar simulator, Newport, USA) was used to give an irradiance of $100 \mathrm{~mW} \mathrm{~cm}$ (equivalent of one sun at AM 1.5G) at the surface of solar cells. The simulator was calibrated using a single crystal Si photodiode (Newport, USA). The current-voltage characteristics of the cell under these conditions were obtained applying an external potential bias to the cell and measuring the generated photocurrent with ZENNIUM workstation (Ref. 2425-C, Zahner Elektrik, Germany). Photovoltaic performance was measured using a metal mask with an aperture area of $0.2 \mathrm{~cm}^{2}$.

The incident photon-to-current conversion efficiency (IPCE) spectra of the cells were recorded using a PC-operated setup consisting of a $300 \mathrm{~W}$ Xenon lamp as a light source (Newport 66902), a monochromator (Newport Cornerstone 74125), a lock-in amplifier (Newport Merlin 70104), set of optical filters and a light chopper. The photon flux of light incident on the samples was normalized using a calibrated silicon detector (Newport 70356). The bias light was supplied by a $100 \mathrm{~W}$ halogen lamp, and the light intensity was adjusted to 0.3 sun by the driven current from a constant current source. Measurements were made at $2 \mathrm{~nm}$ wavelength intervals between 290 and $800 \mathrm{~nm}$.

\subsection{Computational study}

The molecular structures of the dyes $\mathbf{6}-\mathbf{7}$, and $\mathbf{9}$ were optimized without symmetry constraints by density functional theory (DFT) using the CAM-B3LYP [53] functional with the all-electron 6$31 \mathrm{G}(\mathrm{d}, \mathrm{p})$ double- $\zeta$ plus polarization basis sets. The structures were optimized using the polarizable continuum model (PCM) [54,55], as implemented in GAMESS-US [56], to simulate the bulk solvent effects of chloroform. In this model, the solute molecules are placed into a spherical cavity surrounded by a dielectric continuum. In PCM, default van der Waals radii were used for all atoms. Additionally, the geometries of the most stable conformers of dyes $\mathbf{6}, \mathbf{7}$ and $\mathbf{9}$ were also optimized with the B3LYP [57,58] functional and 


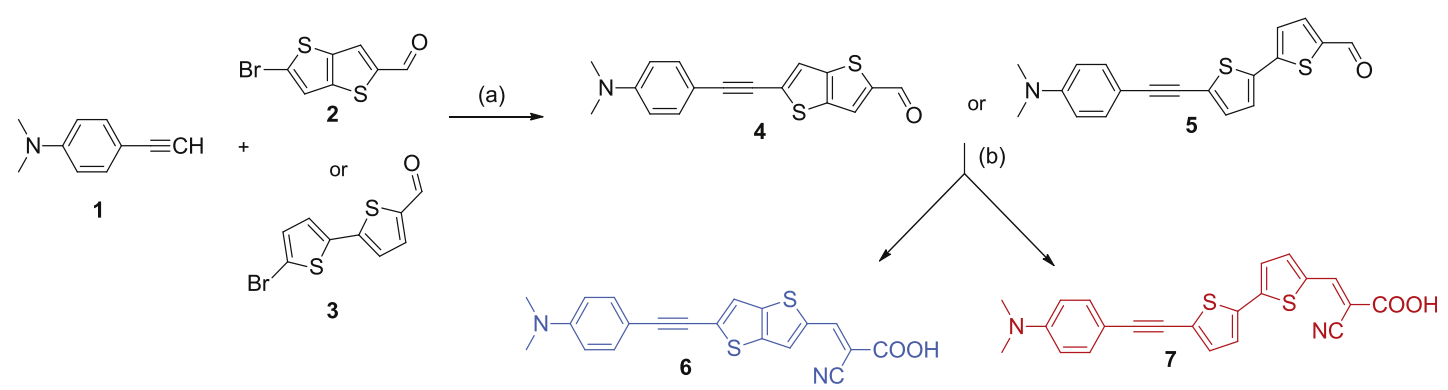

Scheme 1. Reagents and conditions: (a) THF/TEA, $\mathrm{Pd}\left(\mathrm{PPh}_{3}\right)_{2} \mathrm{Cl}_{2}, \mathrm{CuI}, \mathrm{N}_{2}$; (b) EtOH, cyanoacetic acid, TEA.

Table 1

Yields, UV-visible, Fluorescence, IR and ${ }^{1} \mathrm{H}$ NMR data of compounds 4-7 and 9.

\begin{tabular}{|c|c|c|c|c|c|c|c|c|c|c|c|}
\hline \multirow[t]{2}{*}{ Cpds } & \multirow[t]{2}{*}{ Yield (\%) } & \multicolumn{2}{|l|}{$\mathrm{UV}-\mathrm{Vis}^{\mathrm{a}}$} & \multicolumn{3}{|c|}{ Fluorescence $^{a}$} & \multicolumn{4}{|c|}{$\mathrm{IR}^{\mathrm{b}} v\left(\mathrm{~cm}^{-1}\right)$} & \multirow{2}{*}{$\frac{{ }^{1} \mathrm{H} \mathrm{NMR}^{\mathrm{c}} \delta(\mathrm{ppm})}{\mathrm{H} \alpha}$} \\
\hline & & $\lambda_{\max }(\mathrm{nm})$ & $\varepsilon\left(\mathrm{M}^{-1} \mathrm{~cm}^{-1}\right)$ & $\overline{\lambda_{\mathrm{em}}(\mathrm{nm})}$ & Stokes Shift (nm) & $\phi_{\mathrm{F}}$ & $\mathrm{C}=\mathrm{O}$ & $\mathrm{O}-\mathrm{H}$ & $\mathrm{C} \equiv \mathrm{N}$ & $\mathrm{C}=\mathrm{S}$ & \\
\hline 4 & 35 & 409 & 34,705 & 529 & 120 & 0.0016 & 1664 & - & - & - & 9.98 \\
\hline 5 & 77 & 417 & 29,206 & 515 & 98 & 0.006 & - & - & - & - & 9.88 \\
\hline 6 & 53 & 421 & 33,786 & 603 & 182 & 0.026 & 1610 & 3420 & 2194 & - & 8.15 \\
\hline 7 & 81 & 432 & 36,080 & 602 & 170 & 0.050 & - & - & - & - & 8.04 \\
\hline 9 & 31 & 472 & 15,016 & 663 & 191 & 0.075 & 1585 & 3360 & - & 1702 & 8.08 \\
\hline
\end{tabular}

a All the UV-Vis and fluorescence spectra were performed in ethanol, at room temperature, using fluorescein as a quantum yield standard.

b IR spectra were performed in liquid film using chloroform as solvent.

c ${ }^{1} \mathrm{H}$ NMR was performed at $400 \mathrm{MHz}$, using DMSO- $d_{6}$ as solvent.

the same basis set. The Hessian matrix was calculated for all the equilibrium structures to confirm that they are true minima (no imaginary frequencies). The vertical excitation energies were calculated for the major conformers of dyes $\mathbf{6 , 7}$ and $\mathbf{9}$ by timedependent DFT (TD-DFT) using the CAM-B3LYP functional and the $6-311 \mathrm{G}(\mathrm{d}, \mathrm{p})$ triple- $\zeta$ plus polarization basis sets. The bulk solvent effects of chloroform were also taken into account in the calculation of the excitation energies.

\section{Results and discussion}

\subsection{Synthesis and characterization}

Push-pull thiophene derivatives $\mathbf{6}-\mathbf{7}$ and $\mathbf{9}$ were synthesized in order to study the effect of different $\pi$-bridges (ethynyl-2,2' bithiophene or ethynyl-thieno[3,2-b]thiophene) and different anchoring groups (cyanoacetic acid or rhodanine-3-acetic acid) on their optical, redox and photovoltaic properties. All these designed $\pi$-conjugated systems were functionalized with the $\mathrm{N}, \mathrm{N}$-dimethylaniline donor moiety, because of the known high efficiency of this donor group in DSSCs. Ethynyl-2,2'-bithiophene and ethynylthieno[3,2- $b]$ thiophene were used as $\pi$-bridges/spacers due to the excellent optoelectronic properties of thiophene heterocycle such as excellent charge transfer properties, efficient $\pi$-conjugation, low geometric relaxation energy upon oxidation, and also the additional planarity introduced into the dye structure by the ethynyl group which is expected to provide the best photovoltaic performances for the dyes [1-15,35-45,51,52,59-65].
The aldehydes $\mathbf{4}$ and $\mathbf{5}$ were prepared, in fair to good yields (35-77\%), by Sonogashira coupling of 5-bromothieno[3,2-b]thiophene-2-carbaldehyde $\mathbf{2}$ or 5-bromo-2,2'-bithiophene $\mathbf{3}$ with commercially available 4-ethynyl- $N, N$-dimethylaniline. The precursors 2 [47], 3 [48] and 8 [49] were synthesized using the same synthetic methodologies reported by us recently.

The final heterocyclic push-pull conjugated dyes 6-7 were synthesized in good yields (53-81\%) by Knoevenagel condensation of the corresponding aldehyde precursors 4-5 with cyanoacetic acid in refluxing ethanol, using $N$-triethylamine as catalyst (Scheme 1 , Table 1) and dye $\mathbf{9}$ was prepared in $31 \%$ yield by refluxing the aldehyde precursor $\mathbf{8}$ in toluene, with rhodanine-3-acetic acid in the presence of two drops of acetic acid (Scheme 2, Table 1).

Recently the precursor aldehyde $\mathbf{5}$ was reported by Cooke and collaborators through the Sonogashira coupling in 40\% yield using different experimental conditions ( $\mathrm{Pd} / \mathrm{C}$ (10\%); $\mathrm{CuI}, \mathrm{Ph}_{3} \mathrm{P}, \mathrm{K}_{2} \mathrm{CO}_{3}$, $\mathrm{H}_{2} \mathrm{O} /$ DME (1:1) [51]. However, the same compound 5 was prepared by us in a much higher yield (77\%) using different reaction conditions $\left(\mathrm{Pd}\left(\mathrm{PPh}_{3}\right)_{2} \mathrm{Cl}_{2}\right.$, CuI, TEA, THF).

The same investigators reported also the synthesis of dye $\mathbf{7}$ in $28 \%$ yield by condensation of the corresponding precursor aldehyde with 2-cyanoacetic acid in acetonitrile at reflux overnight using piperidine as catalyst. In our experiment the yield of 7 almost triplicated (81\%) by reaction of the precursor aldehyde 5 with 2cyanoacetic acid in the presence of $\mathrm{N}$-triethylamine as catalyst in ethanol at reflux during $6 \mathrm{~h}$.

The heterocyclic compounds 4-7 and $\mathbf{9}$ were completely characterized by standard spectroscopic techniques.
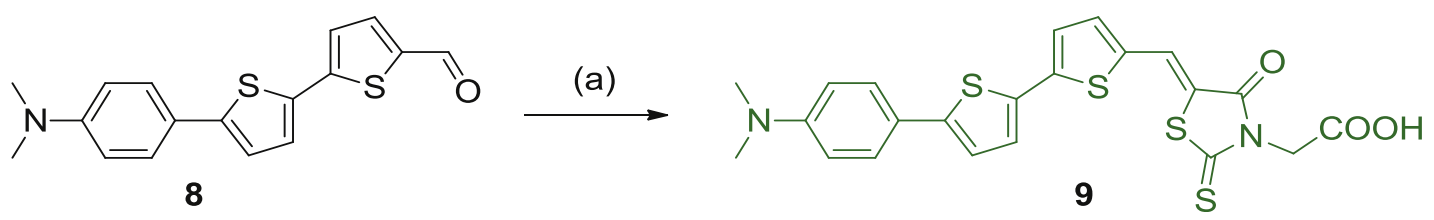

Scheme 2. Reagents and conditions: (a) Toluene, rhodanine-3-acetic acid, acetic acid. 


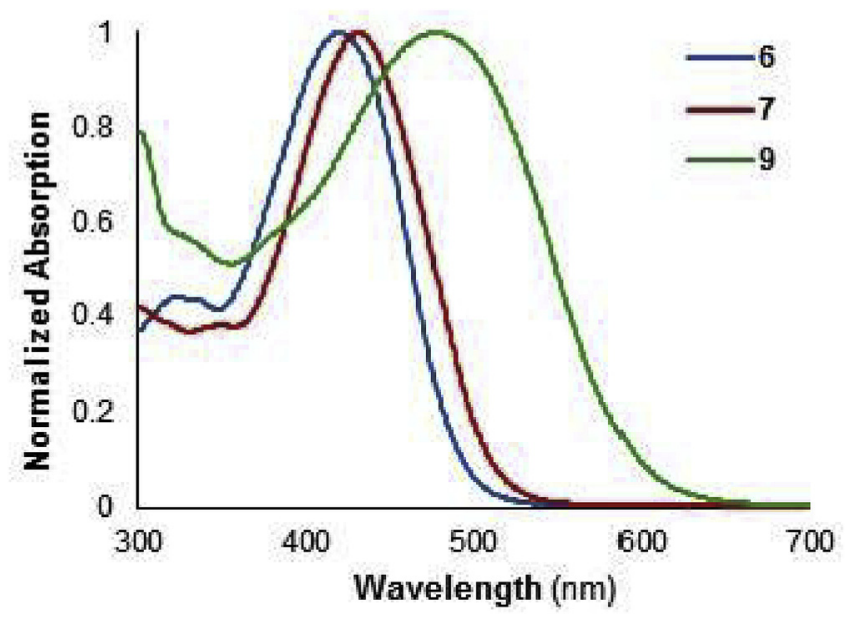

Fig. 1. Normalized absorption spectra of dyes $6-7$ and $\mathbf{9}$ in ethanol $\left(\lambda_{\max }: \mathbf{6}=421 \mathrm{~nm}\right.$; $\mathbf{7}=432 \mathrm{~nm} ; \mathbf{9}=430 \mathrm{~nm}$ ), at room temperature.

\subsection{Optical properties}

The optical properties of push-pull compounds 4-7 and 9 were investigated in ethanol at room temperature and the experimental data are presented in Table 1.

All dyes exhibit a strong, broad band between 409 and $472 \mathrm{~nm}$ that can be assigned to an internal charge transfer process (ICT) between the donor and acceptor groups, which depends on the $\pi$ spacer and on the acceptor/anchoring group.

The substitution of a thienothiophene bridge by a bithiophene spacer, as seen in dye $\mathbf{7}$, induces a bathochromic shift in the longest wavelength absorption of $11 \mathrm{~nm}$ compared with dye $\mathbf{6}$ (Fig. 1). The same trend was also observed for the corresponding precursor aldehydes 4-5. Moreover, compound $\mathbf{7}$ also has the highest molar extinction coefficient, which is advantageous for the light harvesting process of the sensitizer. As expected, the electronic nature of the acceptor groups significantly influences the position of this low-energy absorption band. An increase in the electronic acceptor strength induces a progressive bathochromic shift as can be observed for aldehyde derivatives 4-5 compared to the
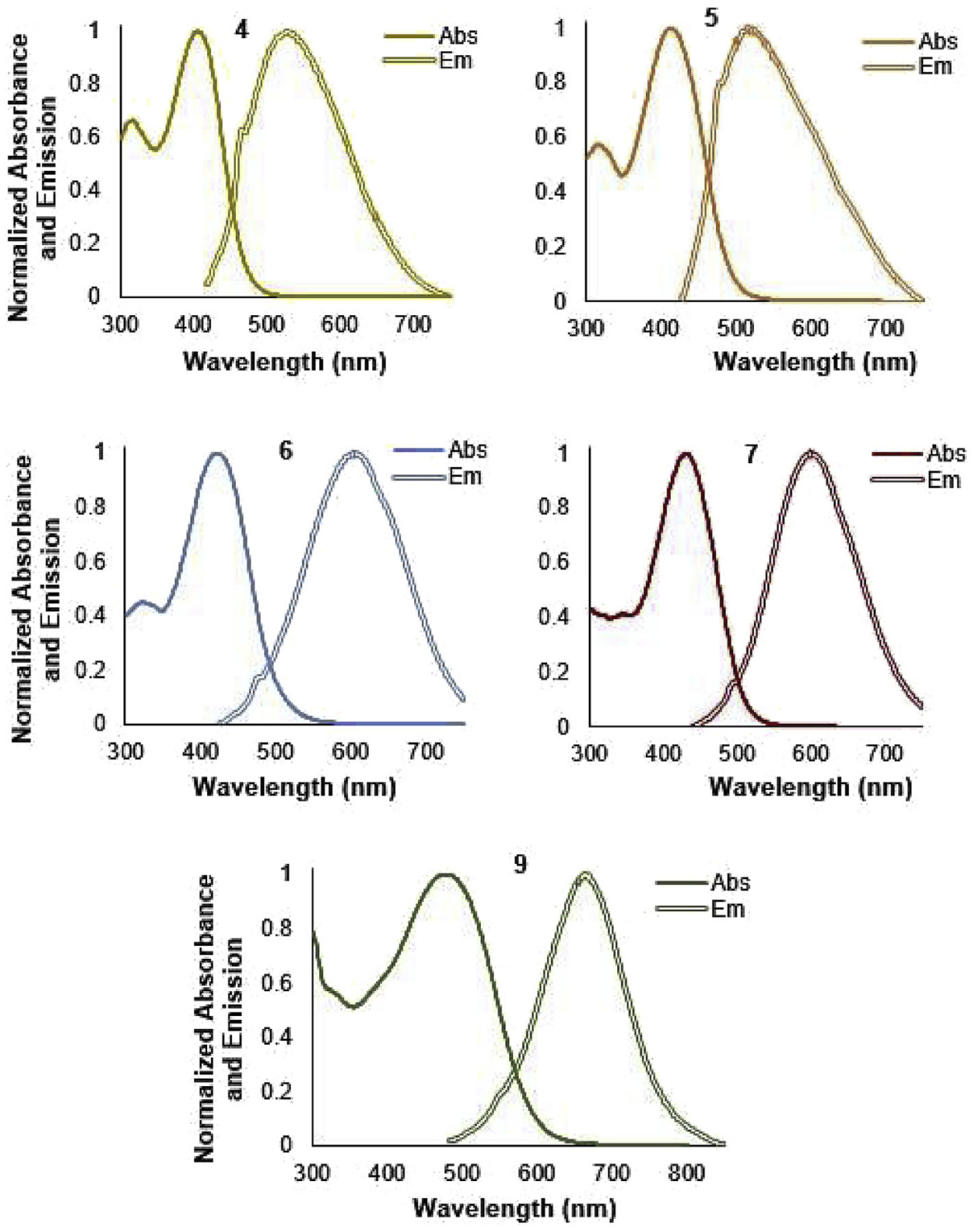

Fig. 2. Normalized absorption and emission spectra for dyes 4-7 and 9, in ethanol. 
corresponding cyanoacetic dyes 6-7 (Table 1). However, the substitution of the ethynyl-bithiophene spacer (7), by the bithiophene system, and additional substitution of the cyanoacetic acceptor group by the rhodanine-3-acetic acid moiety (9), leads to a batochromic shift of the absorption band off $40 \mathrm{~nm}$ compared to dye 7 . This result can be explained considering the loss of the triple bond in the $\pi$-spacer, and the introduction of the rhodanine-3-acetic acid anchoring group which has an opposite effect due its higher conjugation compared to the cyanoacetic group.

Push-pull dyes 6-7 have higher molar extinction coefficients (33,786 to $\left.36,080 \mathrm{M}^{-1} \mathrm{~cm}^{-1}\right)$ when compared to the standard ruthenium ones N3 $\left(13,900 \quad \mathrm{M}^{-1} \mathrm{~cm}^{-1}\right)$ [66] and $\mathbf{N 7 1 9}$ $\left(14,000 \mathrm{M}^{-1} \mathrm{~cm}^{-1}\right)$ [67]. In contrast, the rhodanine dye $\mathbf{9}$ exhibits a lower $\varepsilon$ value of $12,450 \mathrm{M}^{-1} \mathrm{~cm}^{-1}$.

The precursor aldehydes 4-5 and push-pull dyes 6-7 and 9 were excited at the wavelength of maximum absorption, at room temperature, to study their fluorescence properties (Fig. 2). All dyes exhibit weak emissive properties, with relative fluorescence quantum yields ranging from 0.006 to 0.075 . The nature of the acceptor end group significantly influences the fluorescence spectra. As expected, an increase of the strength of the acceptor end group induces a redshift of the emission, as shown in Table 1 and Fig. 2 for the cyanoacetic derivatives 6-7 compared to aldehydes 4-5. All push-pull systems exhibit large Stokes shifts (98-191 nm). Moreover, compounds 6-7 functionalized with a stronger electron acceptor group exhibit higher Stokes shifts (170-191 nm) than the corresponding aldehyde derivatives 4-5 (98-120 nm), which indicates a more pronounced photoinduced ICT.

\subsection{Electrochemical study}

To obtain further insight into the electronic properties of the push-pull dyes, their electrochemical behavior was studied by cyclic voltammetry in degassed DMF using $0.1 \mathrm{M}$ tetrabutylammonium tetrafluoroborate as the supporting electrolyte, a glassy carbon working electrode with a scan rate of $0.1 \mathrm{Vs}^{-1}$, a Pt counter electrode and $\mathrm{Ag} / \mathrm{AgCl}$ reference electrode. The electrochemical studies were performed for compounds $\mathbf{6}$ and $\mathbf{7}$ which exhibit higher efficiency as sensitizers than compound $\mathbf{9}$, and the relevant electrochemical data are summarized in Table 2. The electrochemical study of the well know N719 dye was also performed under the same conditions to compare its electrochemical behavior with dyes 6-7.

It is well known that the electronic nature of the $\pi$-bridge significantly affects the oxidation potential values. Heterocyclic spacers bearing electron rich heterocycles such as thiophene are easier to oxidize due to their stronger electron-donating ability, resulting in a higher HOMO energy level $[22,25]$.

The analysis of the results showed an oxidation process at $+0.67 \mathrm{~V}$ for dye 6 and $+0.44 \mathrm{~V}$ for dye 7, both potentials being more positive than the iodine redox potential $(0.42 \mathrm{~V})$. This is important, since an oxidation potential greater than that of the redox potential of the iodine couple is required to reduce the backward electron transfer to electrolyte solution in DSSCs. Indeed, both devices can show good performance because of their marked difference from the iodide/triiodide redox couple, leading to a better regeneration of the dye after electron injection into the conduction band of $\mathrm{TiO}_{2}$ [68]. Moreover, dye 7 exhibits the lowest value for the oxidation potential, which corresponds to an increase in the HOMO energy $\left(\mathrm{E}_{\mathrm{HOMO}}=-4.83 \mathrm{~V}\right.$ ) compared to compound $6\left(\mathrm{E}_{\mathrm{HOMO}}=-5.06 \mathrm{~V}\right)$ as well as a similar LUMO energy $\left(E_{\text {LUMO }}=-2.65\right.$ for dye 6 and $E_{\text {LUMO }}=-2.68$ for dye 7$)$, due to the stronger electron donating ability of the bithiophene when compared to the thieno[3,2-b]thiophene spacer moiety.

\subsection{Photovoltaic performance of DSSCS}

DSSCs were fabricated using the dyes described above as sensitizers. Details of the device preparation and characterization were described in the experimental section. The photovoltaic performances of DSSCs based on dyes $\mathbf{6}-\mathbf{7}$ and $\mathbf{9}$ characterized under AM 1.5 irradiation ( $100 \mathrm{~mW} \mathrm{~cm}^{-2}$ ) are summarized in Table 3, and the correspondent $I-V$ curves are presented in Fig. 3. The incident photon-to-current conversion efficiency (IPCE) spectra are shown in Fig. 7. The performance of the DSSC fabricated with N719 under the same conditions is also shown for comparison.

Dyes $6-7$ bearing a $N, N$-dimethylaniline donor moiety conjugated with ethynyl-bithiophene or ethynyl-thieno[3,2-b]thiophene spacers and cyanoacetic acid as anchoring/acceptor group exhibit the best efficiencies, $2.63 \%$ and $3.51 \%$, respectively. The better performance of $\mathbf{7}$ dye can be ascribed to a higher photocurrent resulting from having bithiophene as $\pi$-bridge rather than the thienothiophene spacer.

In contrast, dye $\mathbf{9}$, functionalized with a $N, N$-dimethylaminophenyl- group, a bithiophene spacer and a rhodanine-3-acetic acid as acceptor/anchoring group, shows the poorest performance compared with dyes $\mathbf{6}-\mathbf{7}$, with an efficiency of only $0.14 \%$. This can be explained as a consequence of changing the more planar, and more conjugated, ethynyl-bithiophene spacer by the bithiophene bridge, and also due to substitution of the cyanoacetic acid anchoring moiety used in dyes $\mathbf{6 - 7}$ by the rhodanine-3-acetic acid group. In fact, although using rhodanine-3-acetic acid as an anchoring group leads to a significant bathochromic shift due to an increase in the $\pi$-conjugation system, cyanoacrylic is preferable for DSSCs. This happens both due to its coplanarity with respect to spacer unit and good electron coupling with $\mathrm{TiO}_{2}$, but also because the LUMO level of rhodanine-3-acetic acid based dyes is centred on the carbonyl and thiocarbonyl groups, which results in its LUMO being isolated from the $-\mathrm{COOH}$ anchoring group due to the presence of the methylene moiety [69-74].

Until now, sensitizers based on bipyridyl complexes of ruthenium have been widely used in DSSCs due to their very good spectral properties, photostability in operating devices, and high energy conversion efficiencies [75-78]. An excellent example of a

Table 2

Electrochemical data of dyes 6-7 and N719.

\begin{tabular}{|c|c|c|c|c|c|c|c|}
\hline \multirow[t]{2}{*}{ Cpds } & \multicolumn{3}{|c|}{ Reduction $^{\mathrm{a}}$} & \multirow{2}{*}{$\frac{\text { Oxidation }^{\mathrm{a}}}{{ }^{1} \mathrm{E}_{\mathrm{pa}}(\mathrm{V})}$} & \multirow[t]{2}{*}{$\mathrm{E}_{\text {номо }}^{\mathrm{b}}(\mathrm{eV})$} & \multirow[t]{2}{*}{$\mathrm{E}_{\text {LUMO }}{ }^{\mathrm{b}}(\mathrm{eV})$} & \multirow[t]{2}{*}{ Band $\operatorname{gap}^{c}(e V)$} \\
\hline & $-{ }^{1} \mathrm{E}_{\mathrm{pc}}(\mathrm{V})$ & $-{ }^{2} \mathrm{E}_{\mathrm{pc}}(\mathrm{V})$ & $-{ }^{3} E_{p c}(V)$ & & & & \\
\hline 6 & 1.74 & 2.39 & 2.77 & 0.67 & -5.06 & -2.65 & 2.41 \\
\hline 7 & 1.71 & 2.62 & 2.63 & 0.44 & -4.83 & -2.68 & 2.15 \\
\hline N719 & 2.04 & 2.52 & 2.99 & 0.46 & -4.85 & -2.35 & 2.50 \\
\hline
\end{tabular}

a Measurements made in dry DMF containing $1.0 \mathrm{mM}$ in each compounds and $0.1 \mathrm{M}\left[\mathrm{NBu}_{4}\right]\left[\mathrm{BF}_{4}\right]$ as base electrolyte at a carbon working electrode with a scan rate of $0.1 \mathrm{~V} \mathrm{~s}^{-1}$. All $\mathrm{E}$ values are quoted in volts $v s$ the ferrocenium/ferrocene-couple. $E_{\mathrm{pc}}$ and $E_{\mathrm{pa}}$ correspond to the cathodic and anodic peak potentials, respectively.

b $\mathrm{E}_{\mathrm{HOMO}}=-\left(4.39+\mathrm{E}_{\mathrm{ox}}\right)(\mathrm{eV})$ and $\mathrm{E}_{\mathrm{LUMO}}=-\left(\mathrm{E}_{\mathrm{red}}+4.39\right)(\mathrm{eV})$.

c Calculated form the difference between the onset potentials for oxidation and reduction. 
high performance ruthenium polypyridine complex for this is isdithiocyanatobis(4, 4'- dicarboxilic acid - 2, 2'- bipyridine)ruthenium(II), commonly known as the N3 dye [79]. Normally, it is its tetrabutylammonium salt $\mathbf{N 7 1 9}$ that has been used as the standard red dye because of its unmatched performance [80]. This dye is derived from the $\mathbf{N} \mathbf{3}$ form by substituting two protons with two TBA (tetrabutylammonium) cations. Although high efficiency and stability have been achieved with ruthenium-based dyes, the correspondent DSCs devices yield maximum efficiencies by using thick $\mathrm{TiO}_{2}$ films due to low molar extinction coefficients $\left(<20000 \mathrm{M}^{-1} \mathrm{~cm}^{-1}\right.$ ) ascribed to the metal-ligand charge transfer molecular excitation. In contrast, organic dyes generally have larger molar extinction coefficients, allowing the preparation of thinner films, and so minimizing loss during charge transport [81]. On the negative side, they present sharp and narrow absorptions, seriously weakening the light harvesting capabilities. A route to combine the advantages of these two families of dyes is co-sensitization. In addition, co-adsorbing different sensitizers on the $\mathrm{TiO}_{2}$ surface allows investigation of the competition of the dye adsorption on the $\mathrm{TiO}_{2}$ surface leading to formation of a single monolayer on it, since the use of multiple dyes gives a lower coverage of each. Thus, using different percentages of Ru-based dyes mixed with organic ones allows the evaluation of the ease of access that the iodide/triiodide electrolyte may have to the electrons in the $\mathrm{TiO}_{2}$ conduction band.

Based on these ideas, the best performing dyes 6-7 were coadsorbed with different volume fractions of N719. Figs. 4 and 5 and Table 3 show the correspondent $I-V$ curves and the photovoltaic performance parameters of devices containing these mixtures.

In the case of dye $\mathbf{6}$, the best mixture seems to be that with 50 vol\% of each dye. From Table 3 we can see that maximum photocurrent and open-circuit voltage are reached for this case $\left(\eta=3.81 \%, J_{\mathrm{sc}}=9.49 \mathrm{~mA} \mathrm{~cm}{ }^{-2}, V_{\mathrm{oc}}=620 \mathrm{mV}\right)$. The photocurrent enhancement may be explained by the band present at $530 \mathrm{~nm}$ at the UV-Vis spectra - Fig. 6a, while the slight increase in $V_{\text {oc }}$ suggests slower recombination kinetics. The use of N719 co-adsorbed with 6 dye is always beneficial, presenting power conversion efficiencies always greater than just using the $\mathbf{6}$ dye. The broadened UV-Vis absorption spectra of $\mathbf{N 7 1 9}$ and its $\mathrm{TiO}_{2}$ coverage are responsible for the enhanced photovoltaic performances observed in the co-sensitization experiments.

Different conclusions may be made for the case of dye 7. In this case, the use of N719 only becomes advantageous for percentages greater than 50 vol\%, and even above this value the photocurrent maintains constant. This means that the use of the bithiophene $\pi$ bridge instead of a thienothiophene spacer for dye 7 strongly enhances its optical properties, which are further improved only when a large amount of $\mathbf{N 7 1 9}$ is mixed (responsible for the

Table 3

Photovoltaic performance parameters of DSSCs sensitized with individual dyes $6-7$, 9 and its comparison with reference dye N719, and co-adsorption of dyes with N719.

\begin{tabular}{lllll}
\hline Dye & $J_{\mathrm{SC}}\left(\mathrm{mA} \mathrm{cm}^{-2}\right)$ & $V_{\mathrm{OC}}(\mathrm{mV})$ & $F F$ & $\eta(\%)$ \\
\hline $\mathbf{6}$ & 6.56 & 600 & 0.647 & 2.63 \\
$\mathbf{6 / N 7 1 9}-$ 75/25 vol\% & 8.39 & 610 & 0.617 & 3.26 \\
$\mathbf{6 / N 7 1 9}$ - 50/50 vol\% & 9.49 & 620 & 0.629 & 3.81 \\
$\mathbf{6 / N 7 1 9}$ - 25/75 vol\% & 8.50 & 600 & 0.642 & 3.37 \\
$\mathbf{6 / N 7 1 9}$ - seq & 8.51 & 600 & 0.670 & 3.52 \\
$\mathbf{7}$ & 8.45 & 610 & 0.641 & 3.51 \\
$\mathbf{7}[51]$ & 10.5 & 630 & 0.677 & 4.49 \\
7/N719 - 75/25 vol\% & 8.81 & 600 & 0.583 & 3.18 \\
7/N719 - 50/50 vol\% & 11.8 & 610 & 0.603 & 4.65 \\
7/N719 - 25/75 vol\% & 11.7 & 640 & 0.581 & 4.66 \\
7/N719 - seq & 8.41 & 570 & 0.720 & 3.56 \\
$\mathbf{9}$ & 0.52 & 400 & 0.597 & 0.14 \\
$\mathbf{N 7 1 9}$ & 15.58 & 750 & 0.692 & 8.42 \\
\hline
\end{tabular}

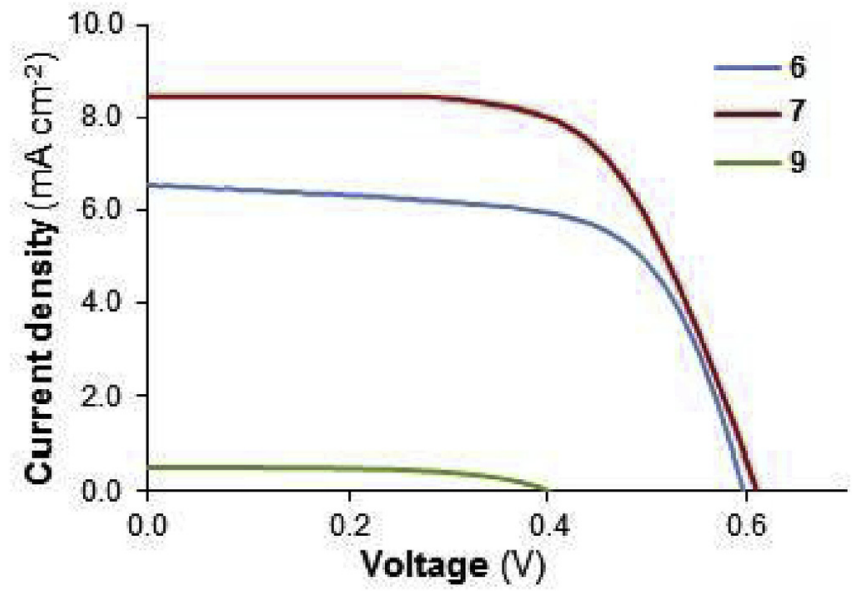

Fig. 3. $I-V$ curves of DSCs prepared with the synthesized $\mathbf{6}-\mathbf{7}$ and $\mathbf{9}$.

appearance of the peak at $530 \mathrm{~nm}$ - Fig. 6b). Indeed, the optimal conversion efficiency for system $7 /$ N719 is found to be approximately the same when using 50 vol\% or 75 vol\% of N719 dye.

Besides co-adsorption with different percentages of N719 dye, sequential co-adsorption consisting of $12 \mathrm{~h}$ dipping time of dye N719, followed by $12 \mathrm{~h}$ in the reported organic dyes was also performed for assessing differences in the type of dye co-adsorption Table 3. Based on IPCE results - Fig. 7, it can be concluded that sequential adsorption of N719/new dye when compared to devices prepared with only each new dye gives a higher quantum efficiency for wavelengths $>450 \mathrm{~nm}$. This is then evidenced by the power conversion efficiency (PCE); for example, dye 6 compared to coadsorption system dye 6/N719 exhibits a PCE increase from 2.63\% to $3.52 \%$. Nevertheless, when comparing cells based on sequential adsorption with the $\mathbf{N 7 1 9}$ reference device, a significant decrease in the PCE occurs, also illustrated by the IPCE response. This means that the adsorption of dyes 6 and 7 are competitive with N719, inducing partial desorption of N719 during the $12 \mathrm{~h}$ dipping time of the organic dyes. Besides, comparing sequential adsorption with co-adsorption with different volume fractions of N719 dye, it can be concluded that dye $\mathbf{6}$ gives almost the same PCE when dyes are adsorbed sequentially, $\eta=3.52 \%$, and for the best co-adsorption composition, which corresponds to 50 vol\% of each dye $\eta=3.81 \%$. In what concerns dye 7 , when adsorbed sequentially, it shows a PCE of $3.56 \%$, which is similar to the PCE of dye $7-3.51 \%$.

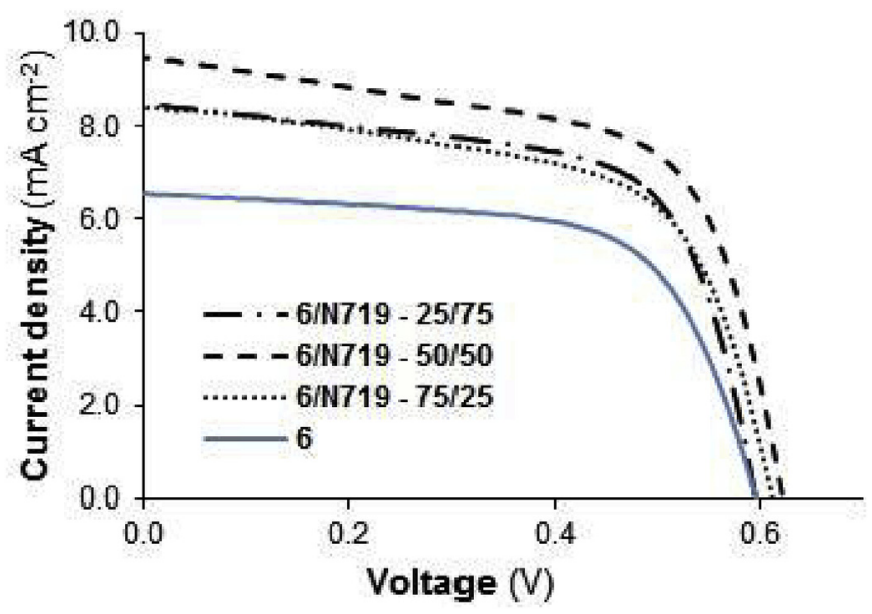

Fig. 4. $I-V$ curves of $\mathbf{6}$ dye co-adsorbed in different volume fractions with N719 dye. 


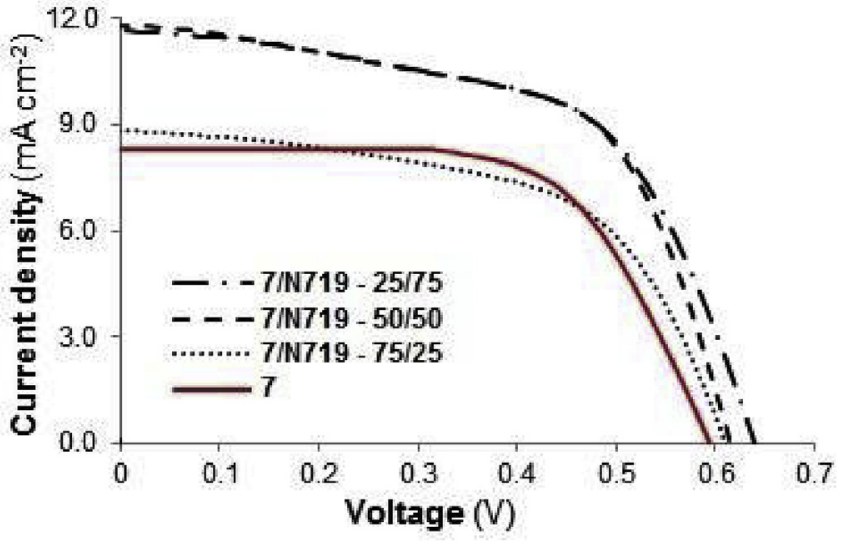

Fig. 5. $I-V$ curves of $\mathbf{7}$ dye co-adsorbed in different volume fractions with N719 dye.

This means that dye $\mathbf{7}$ is preferably adsorbed in the $\mathrm{TiO}_{2}$ surface compared with N719. Between $380 \mathrm{~nm}$ (limit for $\mathrm{TiO}_{2}$ absorption) and $420 \mathrm{~nm}$, both $\mathbf{N 7 1 9}$ and dye $\mathbf{6}$ show the same IPCE. However, when co-adsorbed the quantum efficiency is lower. The same is observed for dye 7. This may suggest that dyes $\mathbf{6}$ and $\mathbf{7}$ pack less efficiently when in the presence of N719.

Finally, the co-sensitization systems either for dyes $\mathbf{6}$ and $\mathbf{7}$ provide evidence for a limited surface coverage of dye on the $\mathrm{TiO}_{2}$ surface after co-sensitization that favors the approach of triiodide ions to the $\mathrm{TiO}_{2}$ surface and enhances the recombination of injected
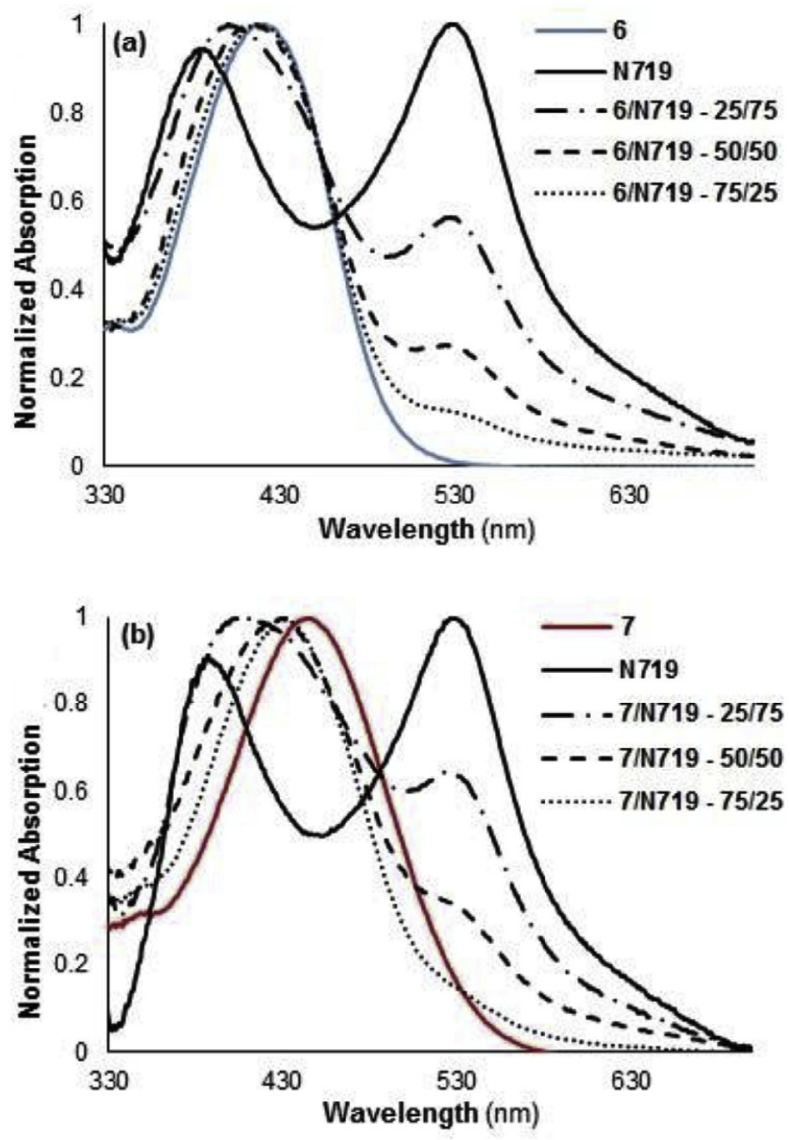

Fig. 6. Normalized absorption spectra in ethanol for co-sensitization systems: a) 6/ N719 and b) 7/N719 dyes.

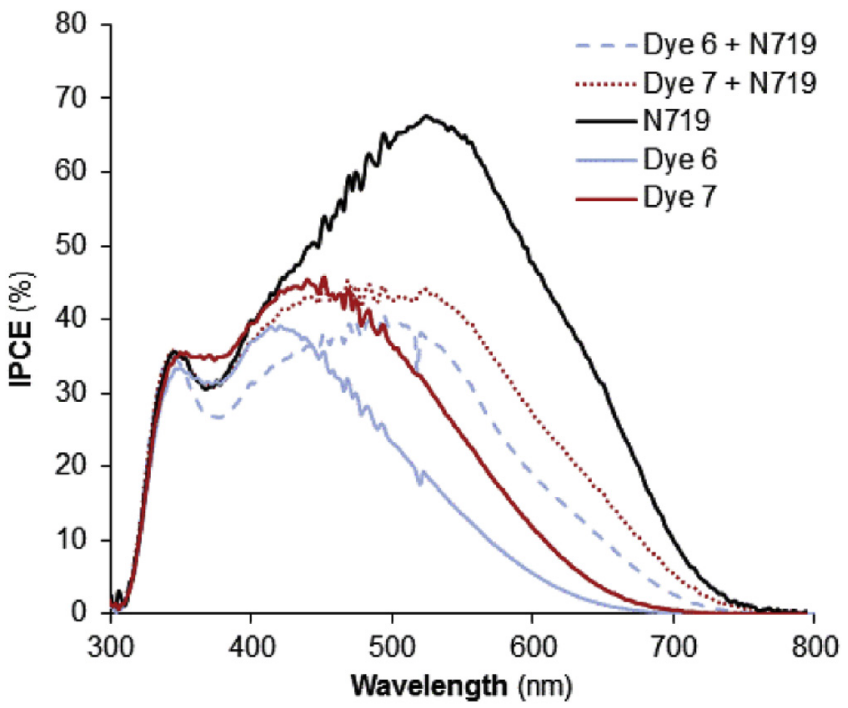

Fig. 7. IPCE spectra of reference dye N719, dyes $\mathbf{6}$ and $\mathbf{7}$ and DSSCs with sequential coadsorption of dyes $\mathbf{6}$ and $\mathbf{7}$.

electrons, since a decrease in $V_{o c}$ is observed when compared with N719 dye alone. Since there is also some photocurrent loss within co-sensitization, in addition to the optical properties of the mixture, there might also be some aggregation of individual dyes under the co-sensitized conditions that decreases their injection efficiencies. These two pathways of efficiency loss give important information for future design of dye synthesis routes.

Previously, Cooke et al. reported the photovoltaic properties of dye 7 which exhibits an efficiency of $4.49 \%$ under their experimental conditions [51]. A thicker $\mathrm{TiO}_{2}$ layer in-house synthesized was used, as well as a different electrolyte and Pt counter-electrode deposited by sputtering. They also performed an additional $\mathrm{TiCl}_{4}$ treatment after $\mathrm{TiO}_{2}$ deposition. These modifications might be responsible for a higher short-circuit photocurrent. The higher performance value reached by us for reference N719 dye is attributed to a higher $F F$ value.

\subsection{Computational study}

To gain insight into the electronic structure and optical properties of compounds, DFT calculations were performed for compounds $6-7$ and 9 .

Compounds 6, 7 and 9 have several possible conformers, differing in the relative arrangement of some of their units. These structures may have different degrees of conjugation, which will influence their optical properties. To determine the lowest energy structures for each of these compounds, a conformational study was carried out at the DFT level. Six conformers of dye $\mathbf{6}$ were considered. These have different relative arrangements between the carboxylic, the cyano and the adjacent thienothiophene groups. For the dye $\mathbf{9}$, in addition to the different possible orientations of the rhodanine heterocycle ring relative to the neighboring thiophene, the cis or trans arrangements between the two thiophene moieties also have to be considered. A computational study was previously published [51] for compound 7, in which two conformers were considered. One has a trans arrangement of the bithiophene moiety and the second conformer has a cis arrangement. The cis form was found to account for only $10 \%$ of the population at equilibrium. In our study we will only consider the trans conformation of $\mathbf{7}$, and we will also investigate the conformers resulting from different arrangements between the thiophene, the 
cyano and the carboxylic groups. A total of six conformers of dye $\mathbf{6}$, six conformers of dye $\mathbf{7}$ and four conformers of dye $\mathbf{9}$, were optimized at the CAM-B3LYP/DFT level, taking into account the bulk solvent (chloroform) effects. The optimized structures for the major conformers are presented in Fig. 8a-c. For dyes $\mathbf{6}$ and $\mathbf{9}$, conformers 6-I and 9-I are the most stable, accounting for 72.6 and $49.6 \%$ of the population at $298 \mathrm{~K}$, respectively (Table 4). These are followed by conformers 6-II and 9-II with 24.6 and $33.1 \%$ of the population, respectively, for each dye. For dye 7 , the major conformer, shown in Fig. 8 b, accounts for $81.6 \%$ of the population (only trans conformers were considered). This structure is different from that studied in Ref. [51], and we found our structure to be more stable by $17.0 \mathrm{~kJ} /$ $\mathrm{mol}(\Delta \mathrm{G})$. However, the differences between the two structures are small and do not significantly affect the main properties calculated for the dye. The optimized geometries of 6-I and 6-II and the major conformer of dye $\mathbf{7}$ are, essentially, planar, which favors the efficient electron transfer from the donor to the acceptor/anchoring moiety. In contrast, the geometry of conformer 9-I (and 9-II) is less planar (Fig. 8b), having a dihedral angle of $26.1^{\circ}$ between the $\mathrm{N}, \mathrm{N}-$ dimethylaminophenyl group and the thiophene unit, and an angle of $15.9^{\circ}$ between the two thiophene rings. The rhodanine heterocycle and the adjacent thiophene ring are approximately coplanar in 9-I and 9-II (torsions in the range $0.3^{\circ}-0.7^{\circ}$ ). The two most stable conformers of dye $\mathbf{9}, \mathbf{9}$-I and $\mathbf{9}$-II, have a trans arrangement of the two thiophene rings. The two cis conformers which are the cis counterparts of 9-I and 9-II were studied and are less stable than 9I by 4.1 and $4.5 \mathrm{~kJ} / \mathrm{mol}$, having populations of 9.2 and $8.1 \%$.

The frontier molecular orbitals of dyes $\mathbf{6 , 7}$ and $\mathbf{9}$ are shown in Fig. 9 (results are shown only for the dominant conformers I of dyes $\mathbf{6}$ and $\mathbf{9}$, but they are similar for conformers II). The highest occupied molecular orbital (HOMO) in dye $\mathbf{6}$ is a $\pi$ orbital localized essentially on the donor ( $\mathrm{N}, \mathrm{N}$-dimethylaniline) and acetylene units and extending to the thienothiophene moiety, while, the lowest unoccupied molecular orbital (LUMO) is a $\pi^{*}$ orbital localized on the acceptor (cyanoacrylic acid) and on the thienothiophene units (and to a smaller extent on the acetylene linker). Similarly, in dye $\mathbf{7}$ the HOMO extends from the donor to the bithiophene moiety and the LUMO is localized mainly on the cyanoacrylic acid acceptor/ anchoring group and extends to the acetylene bridge. In dye $\mathbf{9}$, the HOMO and LUMO are localized mainly on the $\mathrm{N}, \mathrm{N}$-dimethylaminophenyl donor and on the rhodanine-3-acetic acid acceptor, respectively. Therefore, in these dyes, the HOMO-LUMO excitation will result in an overall charge transfer from the donor to the acceptor groups. However, a significant difference occurs between the LUMO orbitals of these dyes. The localization of the LUMO on the anchoring $-\mathrm{COOH}$ group in dyes $\mathbf{6}$ and $\mathbf{7}$ facilitates the injection of the excited electrons into the $\mathrm{TiO}_{2}$ photoelectrode and contributes to the good efficiencies observed for the DSSCs based on these dyes. In contrast, In dye $\mathbf{9}$, the LUMO is not localized on the $-\mathrm{COOH}$ anchoring group, and this hampers an efficient injection of the excited electrons into the $\mathrm{TiO}_{2}$ electrode, and contributes to the low efficiency observed for the DSSC.

The vertical excitation energy for the first singlet excitation has been calculated at the TD-CAM-B3LYP/6-311G(d,p) level for the major conformers of $\mathbf{6 , 7}$ and $\mathbf{9}$ and the results are given in Table 4 . The calculated maximum absorption wavelengths are 452, 468 and $471 \mathrm{~nm}$ for dyes $\mathbf{6}$ (6-I), 7 and $\mathbf{9}$ (9-I), (respectively). The calculations overestimate the maximum absorption wavelengths for dyes

a)
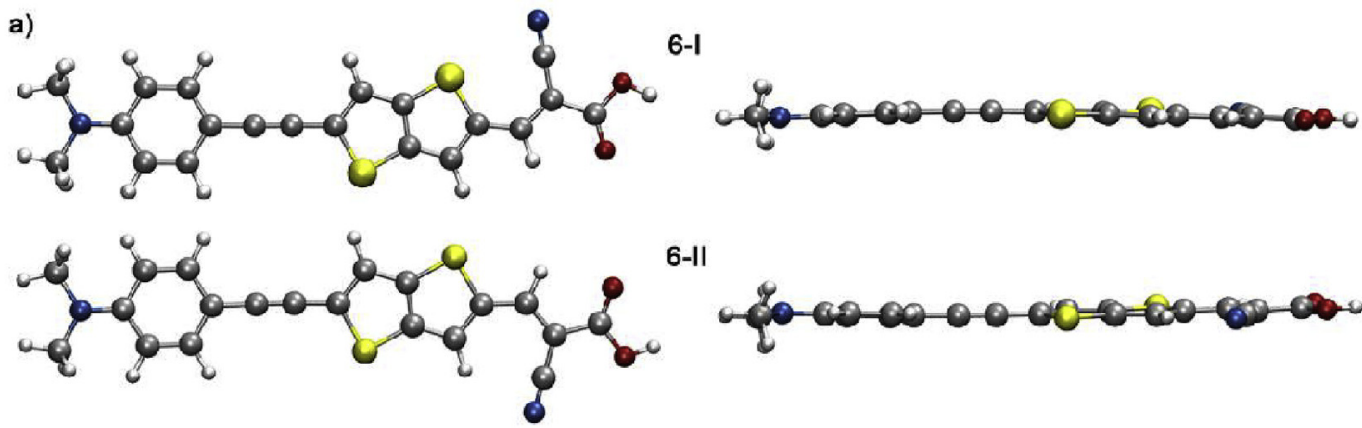

6-II

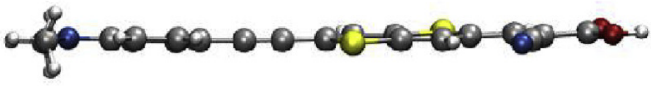

b)

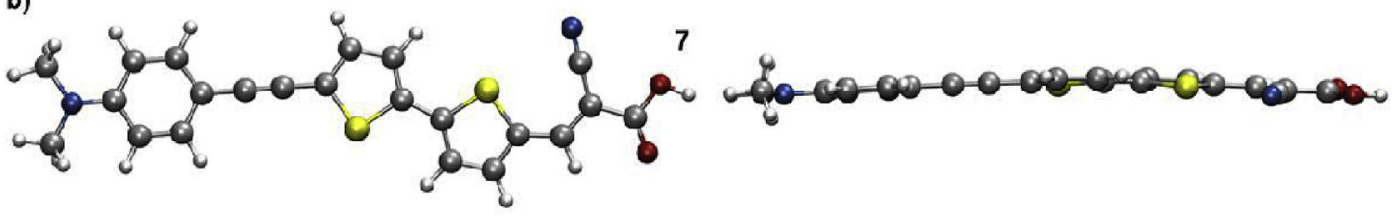

c)
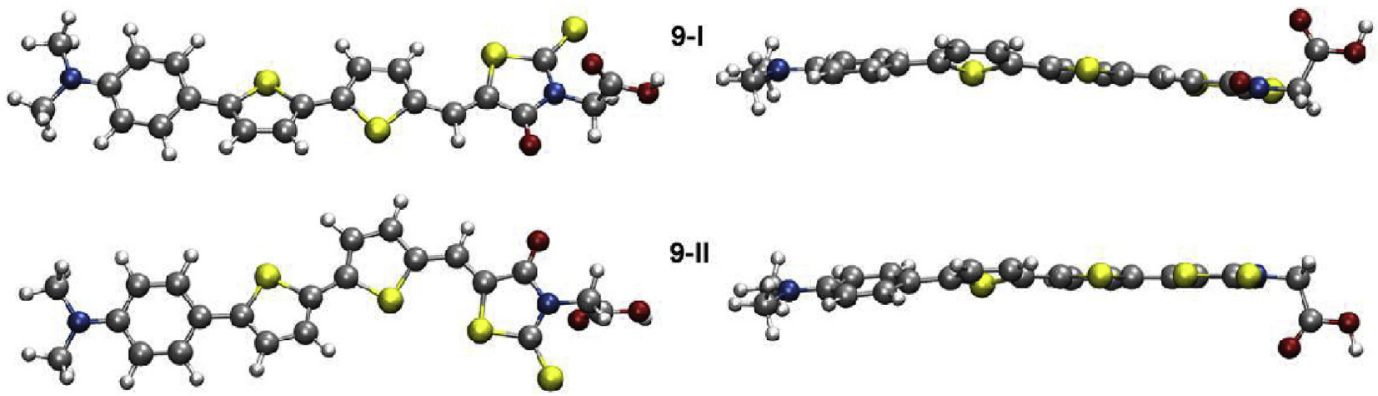

Fig. 8. CAM-B3LYP/6-31G(d,p) optimized geometries of the major conformers of a) dye $\mathbf{6}$; $\mathbf{b}$ ) dye 7; c) dye $\mathbf{9}$. The bulk solvent effects of chloroform were considered in the calculations. 
Table 4

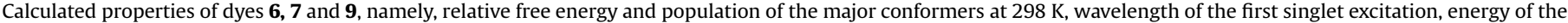
frontier molecular orbitals and HOMO-LUMO gap, compared with the experimental UV-Vis and cyclic voltammetry results.

\begin{tabular}{|c|c|c|c|c|c|c|c|c|c|c|}
\hline Cpds & $\begin{array}{l}\Delta \mathrm{G}(\mathrm{kJ} / \\
\mathrm{mol})\end{array}$ & $\begin{array}{l}P_{298} \\
(\%)\end{array}$ & $\begin{array}{l}\lambda_{\max }(\text { TDDFT })^{\mathrm{a}} \\
(\mathrm{nm})\end{array}$ & $\begin{array}{l}\lambda_{\max }(\mathrm{UV}-\mathrm{Vis}) \\
(\mathrm{nm})\end{array}$ & $\begin{array}{l}\mathrm{E}_{\text {HOMO }}(\mathrm{DFT})^{\mathrm{b}} \\
(\mathrm{eV})\end{array}$ & $\begin{array}{l}\mathrm{E}_{\text {номо }}(\mathrm{CV}) \\
(\mathrm{eV})\end{array}$ & $\begin{array}{l}\mathrm{E}_{\text {LUMO }}(\mathrm{DFT})^{\mathrm{b}} \\
(\mathrm{eV})\end{array}$ & $\begin{array}{l}\mathrm{E}_{\text {LUMo }}(\mathrm{CV}) \\
(\mathrm{eV})\end{array}$ & $\begin{array}{l}\Delta \mathrm{E}_{(\text {HOMO-LUMO) }}(\mathrm{DFT})^{\mathrm{b}} \\
(\mathrm{eV})\end{array}$ & $\begin{array}{l}\Delta \mathrm{E}_{\text {(HOMO-LUMO) }}(\mathrm{CV}) \\
(\mathrm{eV})\end{array}$ \\
\hline 6-I & 0 & 72.6 & 452 & 421 & -5.02 & -5.06 & -2.70 & -2.65 & 2.32 & 2.41 \\
\hline 6-II & 2.68 & 24.6 & 455 & 421 & -5.02 & -5.06 & -2.73 & -2.65 & 2.29 & 2.41 \\
\hline 7 & 0 & $81.6^{\mathrm{c}}$ & 468 & 432 & -4.92 & -4.83 & -2.74 & -2.68 & 2.18 & 2.15 \\
\hline 9-I & 0 & 49.6 & 471 & 472 & -4.86 & d & -2.71 & d & 2.15 & d \\
\hline 9-II & 1.00 & 33.1 & 480 & 472 & -4.86 & d & -2.70 & d & 2.16 & d \\
\hline
\end{tabular}

${ }^{a}$ Results from TD-DFT calculations at the CAM-B3LYP/6-311G(d,p) level of theory.

b Results from ground state calculations on the neutral molecules at the B3LYP/6-31G(d,p) level of theory.

c The \% population indicated for dye $\mathbf{7}$ was calculated considering only the trans conformers.

${ }^{d}$ Not measured because of its low efficiency.
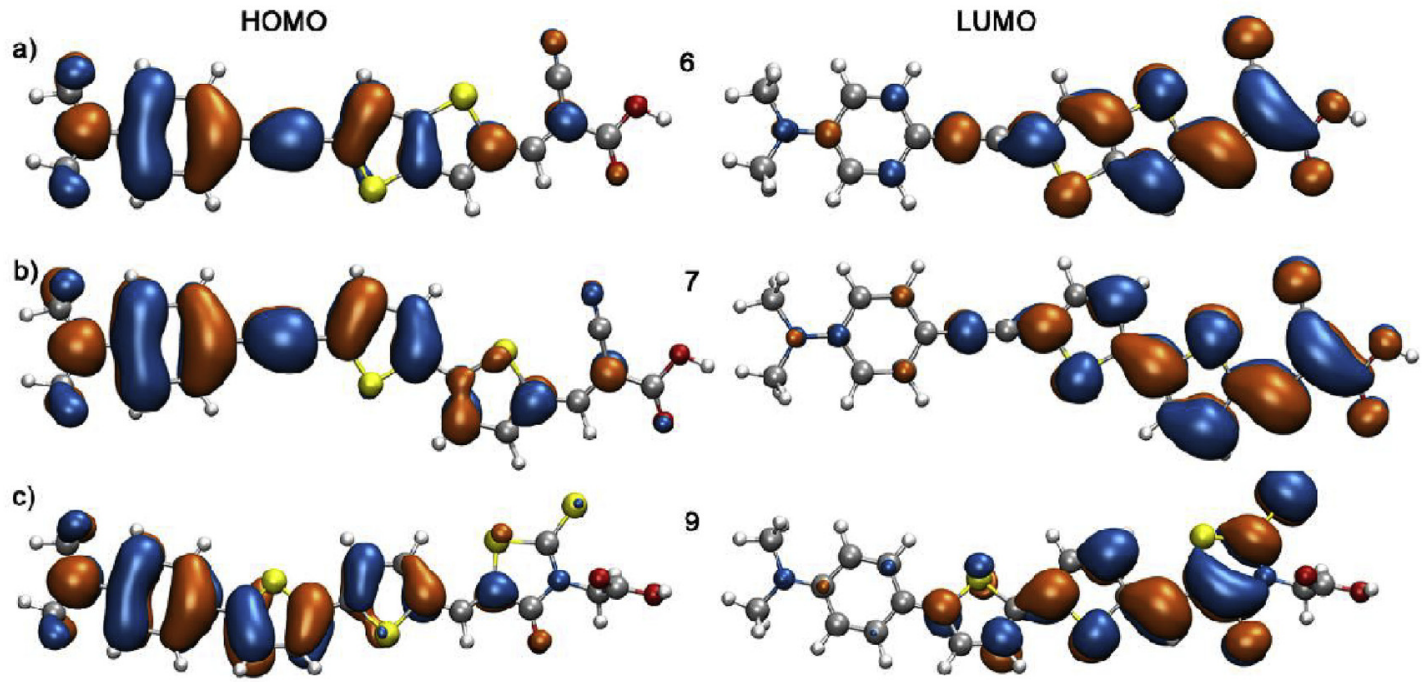

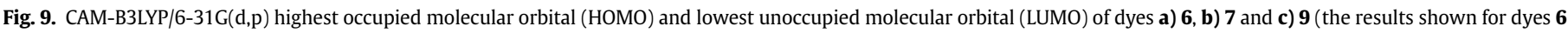
and 9 concern the two dominant conformers 6-I and 9-I). The bulk solvent effects of chloroform were considered in the calculations.

6 and 7 by $31-36 \mathrm{~nm}$ and predict the correct value for dye $\mathbf{9}$. The occurrence of bathochromic shifts on going from dyes 6 to 7, and from 7 to dye $\mathbf{9}$ are also correctly predicted by the TD-DFT calculations.

While the long-range corrected density functionals, such as CAM-B3LYP, seem to perform better for the TD-DFT prediction of excited states with significant charge-transfer character [82], B3LYP is expected to perform better in the calculation of the orbital energies of conjugated polymers [83]. Therefore, we have chosen the B3LYP functional to calculate the energies of the frontier molecular orbitals in our systems. The energies of the HOMO and LUMO orbitals in dyes 6, 7 and 9 have been calculated for the neutral molecules in their ground states, and are given in Table 4 . The energies calculated for dyes $\mathbf{6}$ and $\mathbf{7}$ agree very well with the experimental data obtained from cyclic voltammetry, with absolute errors between 0.00 and $0.05 \mathrm{eV}$ for dye $\mathbf{6}(\mathbf{6 - I})$ and 0.00 and $0.09 \mathrm{eV}$ for dye 7. The HOMO-LUMO gap predicted for dye $\mathbf{9}$ is smaller than those predicted for $\mathbf{6}$ and 7, in accordance with its larger maximum absorption wavelength. This is caused by the extension of the conjugation length due to the presence of the rhodanine-3-acetic acid group.

We also note that the calculated energies in the two conformers $\mathbf{I}$ and $\mathbf{I I}$ in dyes $\mathbf{6}$ and $\mathbf{9}$ are very similar. This is probably a consequence of both conformers I and II, in each dye, having essentially the same degree of conjugation. This may not be the case for conformers which have significantly different degrees of conjugation (for example, the cis conformers in these dyes).

\section{Conclusion}

Dyes 6-7 and $\mathbf{9}$ were prepared by Knoevenagel condensation of the respective aldehyde derivatives $\mathbf{4}-\mathbf{5}$ and $\mathbf{8}$ with commercially available 2 -cyanoacetic acid or with rhodanine-3-acetic acid.

The optical, redox and photovoltaic characterization of the compounds reveals that dye $\mathbf{7}$ bearing an ethynyl-bithiophene spacer shows the best overall conversion efficiency (3.51\%) as sensitizer in nanocrystalline $\mathrm{TiO}_{2}$ DSSCs.

The significantly lower efficiency of dye $\mathbf{9}$ is related to the substitution of cyanoacetic acid for rhodanine-3-acetic acid as an anchoring group.

As expected the co-sensitization systems present higher power conversion than the individual synthesized dyes. For dye $\mathbf{6}$, an improvement of $45 \%$ efficiency was attained with the most advantageous mixture of $50 \%$ of each dye. In the $7 /$ N719 cosensitization system, the introduction of small percentages of N719 is not beneficial at all, but when the addition of more dye starts to increase efficiency, constant photocurrent is quickly reached at about $50 \%$ of each dye, improving efficiency by only $33 \%$. Sequential adsorption was also considered evidencing that partial desorption of N719 occurs during the 12 h dipping time of the organic dyes. Similar power conversion efficiencies were obtained for both co-adsorption methods. 
DFT and TDDFT calculations have been performed on dyes 6-7 and the results obtained are in agreement with the experimental data. The calculations also confirm the importance of the group anchoring the dyes into the $\mathrm{TiO}_{2}$ surface in determining device efficiency as well as the planarity of the dyes.

\section{Acknowledgments}

Thanks are due to: Fundação para a Ciência e a Tecnologia for PhD grants to S. S. M. Fernandes (SFRH/BD/87786/2012), and I. Mesquita (PD/BD/105985/2014) and a postdoctoral grant to L.L.G.Justino. (SFRH/BPD/97026/2013); FEDER-COMPETE for financial support through the CQ/UM PEst-C/QUI/UI0686/2013 (FCOMP01-0124-FEDER-037302); European Research Council (Contract no: 321315) for funding. H. D. Burrows are grateful for funding from Centro de Química de Coimbra, which is supported by the FC through the programmes UID/QUI/UI0313/2013 and COMPETE. The NMR spectrometer Bruker Avance III 400 is part of the National NMR Network and was purchased within the framework of the National Program for Scientific Re-equipment, contract REDE/1517/ RMN/2005 with funds from POCI 2010 (FEDER) and FCT. The authors also thank the Laboratory for Advanced Computing at the University of Coimbra for providing computing resources that have contributed to the research results reported in this paper (URL http://www.lca.uc.pt). The authors would like also to acknowledge A. I. Pereira for sequential co-adsorption devices and Dr. D. Ivanou for IPCE experiments.

\section{References}

[1] N. Robertson, Optimizing dyes for dye-sensitized solar cells, Angew. Chem. Int. Ed. 45 (2006) 2338-2345.

[2] A. Mishra, M.K.R. Fischer, P. Bäuerle, Metal-free organic dyes for dyesensitized solar cells: from structure: property relationships to design rules, sensitized solar cells: from structure: property
Angew. Chem. Int. Ed. 48 (2009) 2474-2499.

[3] Y. Ooyama, Y. Harima, Molecular designs and syntheses of organic dyes for dye-sensitized solar cells, Eur. J. Org. Chem. 2009 (2009) 2903-2934.

[4] A. Hagfeldt, G. Boschloo, L. Sun, L. Kloo, H. Pettersson, Dye-sensitized solar cells, Chem. Rev. 110 (2010) 6595-6663.

[5] Z. Ning, Y. Fu, H. Tian, Improvement of dye-sensitized solar cells: what we know and what we need to know, Energy Environ. Sci. 3 (2010) 1170-1181.

[6] J.N. Clifford, E. Martinez-Ferrero, A. Viterisi, E. Palomares, Sensitizer molecular structure-device efficiency relationship in dye sensitized solar cells, Chem. Soc. Rev. 40 (2011) 1635-1646.

[7] Y.-S. Yen, H.-H. Chou, Y.-C. Chen, C.-Y. Hsu, J.T. Lin, Recent developments in molecule-based organic materials for dye-sensitized solar cells, J. Mater. Chem. 22 (2012) 8734-8747.

[8] Y. Ooyama, Y. Harima, Photophysical and electrochemical properties, and molecular structures of organic dyes for dye-sensitized solar cells, ChemPhysChem 13 (2012) 4032-4080.

[9] R.K. Kanaparthi, J. Kandhadi, L. Giribabu, Metal-free organic dyes for dyesensitized solar cells: recent advances, Tetrahedron 68 (2012) 8383-8393.

[10] B.-G. Kim, K. Chung, J. Kim, Molecular design principle of all-organic dyes for dye-sensitized solar cells, Chem. Eur. J. 19 (2013) 5220-5230.

[11] $Y$. Wu, W. Zhu, Organic sensitizers from D- $\pi-A$ to D-A- $\pi$-A: effect of the internal electron-withdrawing units on molecular absorption, energy levels and photovoltaic performances, Chem. Soc. Rev. 42 (2013) 2039-2058.

[12] S. Ahmad, E. Guillen, L. Kavan, M. Gratzel, M.K. Nazeeruddin, Metal free sensitizer and catalyst for dye sensitized solar cells, Energy Environ. Sci. 6 (2013) 3439-3466.

[13] V. Sugathan, E.J.K. Sudhakar, Recent improvements in dye sensitized solar cells: a review, Renew. Sust. Energy Rev. 52 (2015) 54-64.

[14] I.N. Obotowo, I.B. Obot, U.J. Ekpe, Organic sensitizers for dye-sensitized solar cell (DSSC): properties from computation, progress and future perspectives, J. Mol. Struct. 1122 (2016) 80-87.

[15] S. Chaurasia, J.T. Lin, Metal-free sensitizers for dye-sensitized solar cells, Chem. Rec. 16 (2016) 1311-1336.

[16] J. Maçaira, L. Andrade, A. Mendes, Modeling, simulation and design of dye sensitized solar cells, RSC Adv. 4 (2014) 2830-2844.

[17] L.M. Gonçalves, V.Z. Bermudez, H.A. Ribeiro, A.M. Mendes, Dye-sensitized solar cells: a safe bet for the future, Energy Environ. Sci. 1 (2008) 655-667.

[18] L. Zhang, J.M. Cole, Anchoring groups for dye-sensitized solar cells, ACS Appl. Mater. Interfaces 7 (2015) 3427-3455.

[19] S. Shalini, R.B. Prabhu, S. Prasanna, T.K. Mallick, S. Senthilarasu, Review on natural dye sensitized solar cells: operation, materials and methods, Renew.
Sust. Energy Rev. 51 (2015) 1306-1325.

[20] A. Mahmood, Triphenylamine based dyes for dye sensitized solar cells: a review, Sol. Energy 123 (2016) 127-144.

[21] M.M.M. Raposo, A.M.R.C. Sousa, G. Kirsch, P. Cardoso, M. Belsley, E.M. Gomes, A.M.C. Fonseca, Synthesis and characterization of dicyanovinyl-substituted thienylpyrroles as new nonlinear optical chromophores, Org. Lett. 8 (2006) 3681-3684.

[22] M.M.M. Raposo, A.M.C. Fonseca, M.C.R. Castro, M. Belsley, M.F.S. Cardoso, L.M. Carvalho, P.J. Coelho, Synthesis and characterization of novel diazenes bearing pyrrole, thiophene and thiazole heterocycles as efficient photochromic and nonlinear optical (NLO) materials, Dyes Pigments 91 (2011) $62-73$.

[23] M.R.C. Castro, M. Belsley, A.M.C. Fonseca, M.M.M. Raposo, Synthesis and characterization of novel second-order NLO-chromophores bearing pyrrole as an electron donor group, Tetrahedron 68 (2012) 8147-8155.

[24] B.H. Kim, H.S. Freeman, New N-methyl pyrrole and thiophene based $d-\pi-a$ systems for dye-sensitized solar cells, Dyes Pigments 96 (2013) 313-318.

[25] R.P. Tejada, L. Pelleja, E. Palomares, S. Franco, J. Orduna, J. Garin, R. Andreu, Novel 4H-pyranylidene organic dyes for dye-sensitized solar cells: effect of different heteroaromatic rings on the photovoltaic properties, Org. Electron. 15 (2014) 3237-3250.

[26] M.C.R. Castro, M. Belsley, M.M.M. Raposo, Push-pull second harmonic generation (SHG) chromophores bearing pyrrole and thiazole heterocycles functionalized with strong acceptor moieties: syntheses and characterization, Dyes Pigments 128 (2016) 89-95.

[27] M.C.R. Castro, M. Belsley, M.M.M. Raposo, Synthesis and characterization of push-pull (bi)thienylpyrrole NLOphores with enhanced hyperpolarizabilities, Dyes Pigments 131 (2016) 333-339.

[28] B. O'Regan, M. Gratzel, A low-cost, high-efficiency solar cell based on dyesensitized colloidal $\mathrm{TiO}_{2}$ films, Nature 353 (1991) 737-740.

[29] M. Grätzel, Dye-sensitized solar cells, J. Photochem. Photobiol. C 4 (2003) $145-153$.

[30] M. Grätzel, Conversion of sunlight to electric power by nanocrystalline dyesensitized solar cells, J. Photochem. Photobiol. A 164 (2004) 3-14.

[31] M. Grätzel, Recent advances in sensitized mesoscopic solar cells, Acc. Chem. Res. 42 (2009) 1788-1798.

[32] A. Yella, H.-W. Lee, H.N. Tsao, C. Yi, A.K. Chandiran, M.K. Nazeeruddin, E.W.G. Diau, C.-Y. Yeh, S.M. Zakeeruddin, M. Grätzel, Porphyrin-sensitized solar cells with cobalt (II/III)-Based redox electrolyte exceed 12 percent efficiency, Science 334 (2011) 629-634.

[33] C.A. Bignozzi, R. Argazzi, R. Boaretto, E. Busatto, S. Carli, F. Ronconi, S. Caramori, The role of transition metal complexes in dye sensitized solar devices, Coord. Chem. Rev. 257 (2013) 1472-1492.

[34] B. Pashaei, H. Shahroosvand, M. Gratzel, M.K. Nazeeruddin, Influence of ancillary ligands in dye-sensitized solar cells, Chem. Rev. 116 (2016) 9485-9564.

[35] H. Choi, C. Baik, S.O. Kang, J. Ko, M.-S. Kang, M.K. Nazeeruddin, M. Grätzel, Highly efficient and thermally stable organic sensitizers for solvent-free dyesensitized solar cells, Angew. Chem. 120 (2008) 333-336.

[36] G. Zhang, H. Bala, Y. Cheng, D. Shi, X. Lv, Q. Yu, P. Wang, High efficiency and stable dye-sensitized solar cells with an organic chromophore featuring a binary $\pi$-conjugated spacer, Chem. Commun. (2009) 2198-2200.

[37] H. Choi, I. Raabe, D. Kim, F. Teocoli, C. Kim, K. Song, J.-H. Yum, J. Ko, M.K. Nazeeruddin, M. Grätzel, High molar extinction coefficient organic sensitizers for efficient dye-sensitized solar cells, Chem. Eur. J. 16 (2010) 1193-1201.

[38] S. Paek, H. Choi, C.-W. Lee, M.-S. Kang, K. Song, M.K. Nazeeruddin, J. Ko, Molecular engineering of efficient organic sensitizers incorporating a binary $\pi$-conjugated linker unit for dye-sensitized solar cells, J. Phys. Chem. C 114 (2010) 14646-14653.

[39] H.N. Tsao, J. Burschka, C. Yi, F. Kessler, M.K. Nazeeruddin, M. Grätzel, Influence of the interfacial charge-transfer resistance at the counter electrode in dyesensitized solar cells employing cobalt redox shuttles, Energy Environ. Sci. 4 (2011) 4921-4924.

[40] N. Metri, X. Sallenave, C. Plesse, L. Beouch, P.-H. Aubert, F. Goubard, C. Chevrot, G. Sini, Processable star-shaped molecules with triphenylamine core as holetransporting materials: experimental and theoretical approach, J. Phys. Chem. C 116 (2012) 3765-3772.

[41] Y. Wu, M. Marszalek, S.M. Zakeeruddin, Q. Zhang, H. Tian, M. Grätzel, W. Zhu, High-conversion-efficiency organic dye-sensitized solar cells: molecular engineering on $\mathrm{d}-\mathrm{a}-\pi$-a featured organic indoline dyes, Energy Environ. Sci. 5 (2012) 8261-8272.

[42] S. Cai, G. Tian, X. Li, J. Su, H. Tian, Efficient and stable DSSC sensitizers based on substituted dihydroindolo[2,3-b]carbazole donors with high molar extinction coefficients, J. Mater. Chem. A 1 (2013) 11295-11305.

[43] P. Gao, H.N. Tsao, C. Yi, M. Grätzel, M.K. Nazeeruddin, Extended $\pi$-bridge in organic dye-sensitized solar cells: the longer, the better? Adv. Energy Mater. 4 (2014) $1-7$.

[44] K. Kakiage, Y. Aoyama, T. Yano, T. Otsuka, T. Kyomen, M. Unno, M. Hanaya, An achievement of over $12 \%$ efficiency in an organic dye-sensitized solar cell, Chem. Commun. 50 (2014) 6379-6381.

[45] M.-W. Lee, J.-Y. Kim, D.-H. Lee, M.J. Ko, Novel D- $\pi$-A organic dyes with thieno [3,2-b]thiophene-3,4-ethylenedioxythiophene unit as a $\pi$-bridge for highly efficient dye-sensitized solar cells with long-term stability, ACS Appl. Mater. Interfaces 6 (2014) 4102-4108. 
[46] K. Kakiage, Y. Aoyama, T. Yano, K. Oya, J.-I. Fujisawabi, M. Hanaya, Highlyefficient dye-sensitized solar cells with collaborative sensitization by silylanchor and carboxy-anchor dyes, Chem. Comm. 51 (2015) 15894-15897.

[47] M.M.M. Raposo, C. Herbivo, V. Hugues, G. Clermont, M.C.R. Castro, A. Comel, M. Blanchard-Desce, Synthesis, fluorescence and two-photon absorption properties of push-pull 5-aryl[3,2-b]thienothiophene derivatives, Eur. J. Org. Chem. 31 (2016) 5263-5273.

[48] S.P.G. Costa, R.M.F. Batista, M.M.M. Raposo, Synthesis and photophysical characterization of new fluorescent bis-amino acids bearing a heterocyclic bridge containing benzoxazole and thiophene, Tetrahedron 64 (2008) 9733-9737.

[49] C. Herbivo, A. Comel, G. Kirsch, M.M.M. Raposo, Synthesis of 5-aryl-5'-formyl2,2'-bithiophenes as new precursors for nonlinear optical (NLO) materials, Tetrahedron 65 (2009) 2079-2086.

[50] J.Q. Umberger, V.K. LaMer, The kinetics of diffusion controlled molecular and ionic reactions in solution as determined by measurements of the quenching of fluorescence, J. Am. Chem. Soc. 67 (1945) 1099-1109.

[51] M. Al-Eid, S. Lim, K.-W. Park, B. Fitzpatrick, C.-H. Han, K. Kwak, J. Hong, G. Cooke, Facile synthesis of metal-free organic dyes featuring a thienylethynyl spacer for dye sensitized solar cells, Dyes Pigments 104 (2014) 197-203.

[52] C.M. Cardona, W. Li, A.E. Kaifer, D. Stockdale, G.C. Bazan, Electrochemica considerations for determining absolute frontier orbital energy levels of conjugated polymers for solar cell applications, Adv. Mater. 23 (2011) 2367-2371

[53] T. Yanai, D.P. Tew, N.C. Handy, A new hybrid exchange-correlation functional using the Coulomb-attenuating method (CAM-B3LYP), Chem. Phys. Lett. 393 (2004) 51-57.

[54] S. Miertus, E. Scrocco, J. Tomasi, Electrostatic interaction of a solute with a continuum. A direct utilization of $\mathrm{AB}$ initio molecular potentials for the prevision of solvent effects, Chem. Phys. 55 (1981) 117-129.

[55] J. Tomasi, B. Mennucci, R. Cammi, Quantum mechanical continuum solvation models, Chem. Rev. 105 (2005) 2999-3093.

[56] M.W. Schmidt, K.K. Baldridge, J.A. Boatz, S.T. Elbert, M.S. Gordon, J.H. Jensen, S. Koseki, N. Matsunaga, K.A. Nguyen, S.J. Su, T.L. Windus, M. Dupuis, J.A. Montgomery, General atomic and molecular electronic structure system, J. Comput. Chem. 14 (1993) 1347-1363.

[57] A.D. Becke, Density-functional thermochemistry III the role of exact exchange, J. Chem. Phys. 98 (1993) 5648-5652.

[58] C. Lee, W. Yang, R.G. Parr, Development of the Colle-Salvetti correlation-energy formula into a functional of the electron density, Phys. Rev. B Condens. Mat. 37 (1988) 785-789.

[59] M.E. Cinar, T. Ozturk, Thienothiophenes, dithienothiophenes, and thienoacenes: syntheses, oligomers, polymers, and properties, Chem. Rev. 115 (2015) 3036-3140.

[60] H. Liu, F. Wu, B. Zhao, L. Meng, G. Wang, J. Zhang, P. Shen, S. Tan, Synthesis and photovoltaic properties of the acceptor pended push-pull conjugated polymers incorporating thieno[3,2-b] thiophene in the backbone chain or side chains, Dyes Pigments 120 (2015) 44-51.

[61] M.-W. Lee, J.-Y. Kim, D.-H. Lee, M.J. Ko, Novel D- $\pi$-A organic dyes with thieno [3,2-b]thiophene-3,4-ethylenedioxythiophene unit as a $\pi$-bridge for highly efficient dye-sensitized solar cells with long-term stability, ACS Appl. Mater Interfaces 6 (2014) 4102-4108.

[62] L. Pellejà, R. Dominguez, A. Aljarilla, J.N. Clifford, P. de la Cruz, F. Langa, E. Palomares, Use of thienylenevinylene and ethynyl molecular bridges in organic dyes for dye-sensitized solar cells: implications for device performance, ChemElectroChem 1 (2014) 1126-1129.

[63] C. Teng, X. Yang, C. Yang, H. Tian, S. Li, X. Wang, A. Hagfeldt, L. Sun, Influence of triple bonds as $\pi$-spacer units in metal-free organic dyes for dye-sensitized solar cells, J. Phys. Chem. C 114 (2010) 11305-11313.

[64] C. Teng, X. Yang, C. Yang, S. Li, M. Cheng, A. Hagfeldt, L. Sun, Molecular design of anthracene-bridged metal-free organic dyes for efficient dye-sensitized solar cells, J. Phys. Chem. C 114 (2010) 9101-9110.
[65] S.S.M. Fernandes, M.C.R. Castro, I. Mesquita, L. Andrade, A. Mendes, M.M.M. Raposo, Synthesis and characterization of novel thieno[3,2-b]thiophene based metal-free organic dyes with different heteroaromatic donor moieties as sensitizers for dye-sensitized solar cells, Dyes Pigments 136 (2017) 46-53.

[66] T. Horiuchi, H. Miura, S. Uchida, Highly-efficient metal-free organic dyes for dye-sensitized solar cells, Chem. Commun. 24 (2003) 3036-3037.

[67] P. Wang, C. Klein, R. Humphry-Baker, S.M. Zakeeruddin, M. Grätzel, A high molar extinction coefficient sensitizer for stable dye-sensitized solar cells, J. Am. Chem. Soc. 127 (2005) 808-809.

[68] A. Hagfeldt, M. Grätzel, Light-induced redox reactions in nanocrystalline systems, Chem. Rev. 95 (1995) 49-68.

[69] L. Zhang, J.M. Cole, Anchoring groups for dye-sensitized solar cells, ACS Appl. Mater. Interfaces 7 (2015) 3427-3455.

[70] Z. Wan, C. Jia, Y. Duan, J. Zhang, Y. Lin, Y. Shi, Effects of different acceptors in phenothiazine-triphenylamine dyes on the optical, electrochemical, and photovoltaic properties, Dyes Pigments 94 (2012) 150-155.

[71] S. Ramkumar, S. Manoharan, S. Anandan, Synthesis of d- $(\tau-a)_{2}$ organic chromophores for dye-sensitized solar cells, Dyes Pigments 94 (2012) 503-511.

[72] B. Liu, W. Li, B. Wang, X. Li, O. Liu, Y. Naruta, W. Zhu, Influence of different anchoring groups in indoline dyes for dye sensitized solar cell: electroninjection, impedance and charge recombination, J. Power Sources 234 (2013) 139-146.

[73] X.M. Ma, W.J. Wu, Q. Zhang, F.L. Guo, F.S. Meng, Hua, Novel fluoranthene dyes for efficient dye-sensitized solar cells, Dyes Pigments 82 (2009) 353-359.

[74] T. Marinado, D.P. Hagberg, M. Hedlund, T. Edvinsson, E.M.J. Johansson, G. Boschloo, Rhodanine dyes for dye-sensitized solar cells: spectroscopy, energy levels and photovoltaic performance, Phys. Chem. Chem. Phys. 11 (2009) 133-141.

[75] J. Desilvestro, M. Graetzel, L. Kavan, J. Moser, J. Augustynski, Highly efficient sensitization of titanium dioxide, J. Am. Chem. Soc. 107 (1985) 2988-2990.

[76] N. Vlachopoulos, P. Liska, J. Augustynski, M. Graetzel, Very efficient visible light energy harvesting and conversion by spectral sensitization of high surface area polycrystalline titanium dioxide films, J. Am. Chem. Soc. 110 (1988) $1216-1220$

[77] R. Argazzi, C.A. Bignozzi, T.A. Heimer, F.N. Castellano, G.J. Meyer, Enhanced spectral sensitivity from ruthenium(II) polypyridyl based photovoltaic devices, Inorg. Chem. 33 (1994) 5741-5749.

[78] O. Kohle, S. Ruile, M. Grätzel, Ruthenium(II) charge-transfer sensitizers containing 4,4'-Dicarboxy-2,2'-bipyridine. Synthesis, properties, and bonding mode of coordinated thio- and selenocyanates, Inorg. Chem. 35 (1996) 4779-4787.

[79] M.K. Nazeeruddin, A. Kay, I. Rodicio, R. Humphry-Baker, E. Mueller, P. Liska, N. Vlachopoulos, M. Graetzel, Conversion of light to electricity by cisX2bis(2,2'-bipyridyl-4,4'-dicarboxylate)ruthenium(II) charge-transfer sensitizers (X $=\mathrm{Cl}-, \mathrm{Br}-, \mathrm{I}-, \mathrm{CN}-$, and $\mathrm{SCN}-$ ) on nanocrystalline titanium dioxide electrodes, J. Am. Chem. Soc. 115 (1993) 6382-6390.

[80] M.K. Nazeeruddin, F. De Angelis, S. Fantacci, A. Selloni, G. Viscardi, P. Liska, S. Ito, B. Takeru, M. Grätzel, Combined experimental and DFT-TDDFT computational study of photoelectrochemical cell ruthenium sensitizers, J. Am. Chem. Soc. 127 (2005) 16835-16847.

[81] Y. Wu, M. Marszalek, S.M. Zakeeruddin, Q. Zhang, H. Tian, M. Gratzel, W. Zhu, High-conversion-efficiency organic dye-sensitized solar cells: molecular engineering on D-A- $\pi$-A featured organic indoline dyes, Energy Environ. Sci. 5 (2012) 8261-8272.

[82] L. Pandey, C. Doiron, J.S. Sears, J.-L. Brédas, Lowest excited states and optical absorption spectra of donor-acceptor copolymers for organic photovoltaics: a new picture emerging from tuned long-range corrected density functionals, Phys. Chem. Chem. Phys. 14 (2012) 14243-14248.

[83] T.M. McCormick, C.R. Bridges, E.I. Carrera, P.M. DiCarmine, G.L. Gibson, J. Hollinger, L.M. Kozycz, D.S. Seferos, Conjugated polymers: evaluating DFT Methods for more accurate orbital energy modeling, Macromolecules 46 (2013) 3879-3886. 